ECCOMAS

Proceedia $6^{\text {th }}$ ECCOMAS Thematic Conference on Computational Methods in Structural Dynamics and Earthquake Engineering

M. Papadrakakis, M. Fragiadakis (eds.) Rhodes Island, Greece, 15-17 June 2017

\title{
IMPLEMENTATION OF THE KDAMPER CONCEPT TO WIND TURBINE TOWERS
}

\author{
K. A. Kapasakalis ${ }^{1 *}$, E. I. Sapountzakis ${ }^{1}$, I. A. Antoniadis ${ }^{2}$ \\ ${ }^{1}$ Institute of Structural Analysis and Antiseismic Reasearch \\ School of Civil Engineering, National Technical University of Athens \\ Zografou Campus, GR-157 80 Athens, Greece \\ kostiskapasakalis@hotmail.com,cvsapoun@central.ntua.gr \\ ${ }^{2}$ Mechanical Design and Control Systems Section \\ Mechanical Engineering Department, National Technical University of Athens \\ Zografou Campus, GR-157 80 Athens, Greece \\ antogian@central.ntua.gr
}

Keywords: KDamper, Wind turbines, negative stiffness elements, structural control, vibration isolation, Tuned Mass Dampers.

\begin{abstract}
A novel passive vibration isolation and damping concept is implemented to wind turbine towers in order to minimize their response, under wind or seismic loads. This concept, called KDamper, constitutes a combination of the classic Tunned Mass Damper isolation system (TMD) with negative stiffness elements. The formulation of the linear and non-liner dynamic problem is a prerequisite. A parametric study is performed to determine the optimal parameters of the KDamper which degradate the response. For this scope, the calculation process of the aerodynamic load that exerts along the tower of the wind turbine is described. A comparison with a non-isolated wind turbine, as long as with a TMD isolated wind turbine indicates that KDamper is a promising isolation system, offering numerous advantages, such as increased damping and simple technological implementations.
\end{abstract}




\section{INTRODUCTION}

As wind power continues its rapid growth worldwide, wind farms are likely to comprise a significant portion of the total production of wind energy, and may even become a sizable contributor to the total electricity production in some countries. The high quality wind resource and the proximity to load centers make wind energy a compelling proposition. A critical factor in the design of wind turbines is their dynamic response, due to wind loads and seismic excitations. A way to extend the feasibility of the wind turbine towers is by means of structural control, in which external devises are installed in order to reduce the dynamic response. For structural control of fixed wind turbines, resonant damping is the concept most widely used by the industry, and it is also the damping concept that has received the most attention in the literature. Installation of a resonant damper like a Tuned Mass Damper (TMD) have been shown to degradate the response of the wind turbine. In order to be effective, a resonant damper like a TMD should be installed where the absolute motion of the targeted vibration mode is large, wich is at the top of the tower or inside the nacelle.

The Tuned Mass Damper (TMD) has a long history, already more than 100 years. The TMD concept was first applied by (Frahm, 1909 [8]). A theory for the TMD was presented later in the paper by (Ormondroyd and Den Hartog, 1928 [16]) . A detailed discussion of optimal tuning and damping parameters appears in (Den Hartog, 1956 [5]). Since then, numerous applications of various forms of TMDs have been reported. Some recent examples include vibration absorption in seismic or other forms of excitation of structures (Debnath et al., 2015 [4]), wind and wave excitation in wind turbines by and torsional vibrations in rotating and reciprocating machines by (Mayet and Ulbrich, 2015 [14]). TMDs are available in various physical forms, including solids, liquids, or even active implementations (Younespour and Ghaffarzadeh, 2015 [22]). The essential limitation of the TMD is that a large oscillating mass is required in order to achieve significant vibration reduction. Among others, this has prohibited the usage of TMDs in the automotive or aerospace sector.

A parallel direction to the various TMD approaches is the concept of introducing negative stiffness elements (or 'anti-springs') for vibration isolation. This concept has also a long history, being first introduced in the pioneering publication of (Molyneaux, 1957 [15]), as well as in the milestone developments of (Platus, 1999 [17]). The central concept of these approaches is to significantly reduce the stiffness of the isolator and consequently to reduce the natural frequency of the system even at almost zero levels (Carella et al., 2007 [2]), being thus called "Quazi Zero Stiffness" (QZS) oscillators. In this way, the transmissibility of the system for all operating frequencies above the natural frequency is reduced, resulting to enhanced vibration isolation. An initial comprehensive review of such designs can be found in (Ibrahim, 2008 [10]). However, Quazi Zero Stiffness (QZS) oscillators suffer from their fundamental requirement for a drastic reduction of the stiffness of the structure almost to negligible levels, which limits the static load capacity of such structures.

A novel passive vibration isolation and damping concept, KDamper is proposed in Antoniadis et al. [1] incorporating negative stiffness elements in the classical Tuned Mass Damper isolation system (TMD), which can exhibit extraordinary damping properties, without presenting the drawbacks of the traditional linear oscillator, or of the 'zero-stiffness' designs. This oscillator is designed to present the same overall (static) stiffness as a traditional reference original oscillator. However, it differs both from the original SDoF oscillator, as well as from the known negative stiffness oscillators, by appropriately redistributing the individual stiffness elements and by reallocating the damping. The KDamper always indicates better isolation properties than a TMD damper with the same additional mass. Instead of increasing the additional mass, the vibration isolation capability of the KDamper can be increased by in- 
creasing the value of the negative stiffness element. Although the proposed oscillator incorporates a negative stiffness element, it is designed to be both statically and dynamically stable. Once such a system is designed according to the approach proposed in (Antoniadis et al., 2015 [1]), it is shown to exhibit an extraordinary damping behaviour.

\section{GENERAL CONCEPT FOR LINEAR DAMPERS}

Figure 1 presents the basic layout of the fundamental vibration isolation and damping concepts to be considered. They are all designed to minimize the response $x(t)$ of an undamped SDoF system of mass $m$ and static stiffness $k$ of to a base excitation of $x_{G}(t)$.

The concept of the QZS oscillator, presented in Figure 1.a, is to add a negative stiffness element $k_{N}$ in parallel to the original stiffness $k$ of the system, so that the overall stiffness of the system becomes lower than the original stiffness of the system.

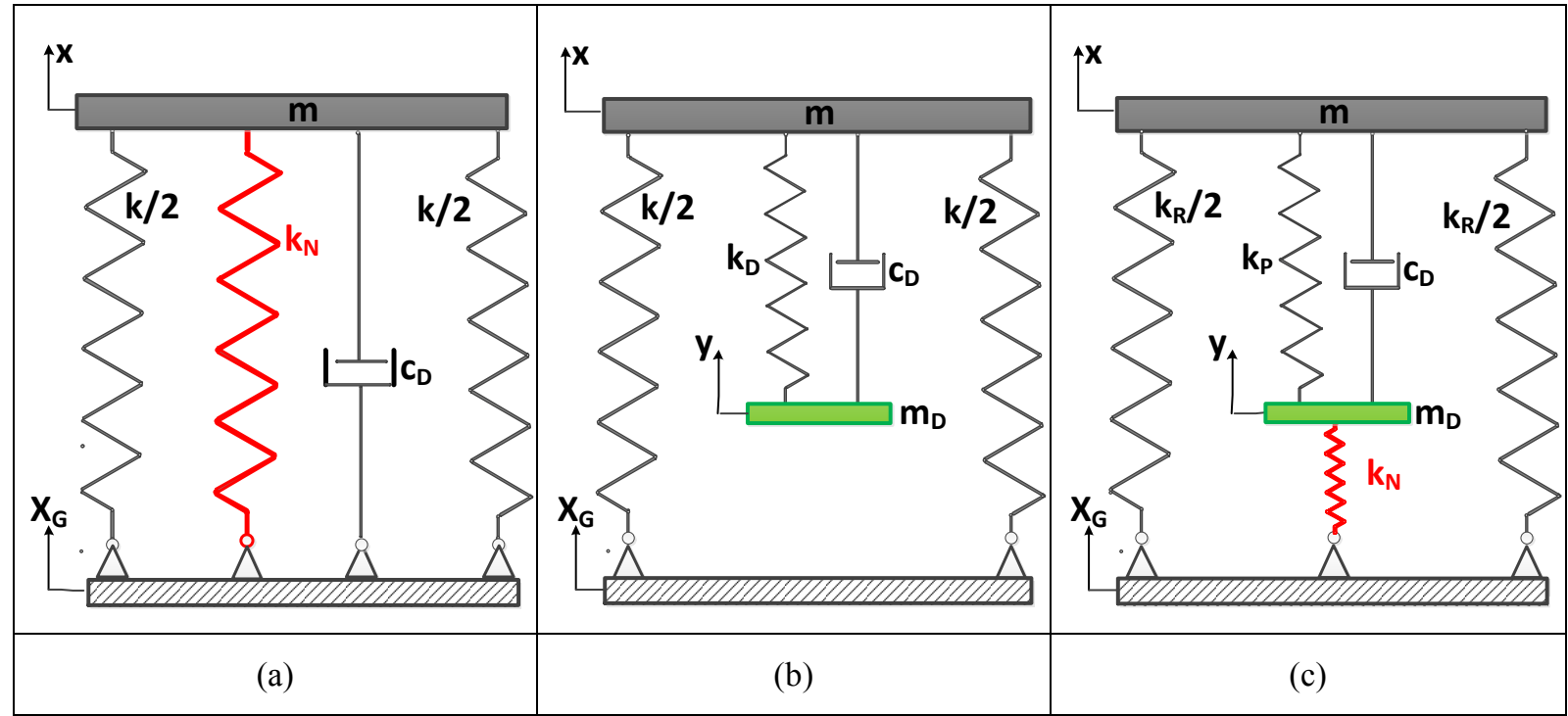

Figure 1: Schematic presentation of the considered vibration absorption concepts (a) Quasi-Zero Stiffness (QZS) oscillator, (b) Tunned Mass Damper(TMD), (c) KDamper.

However, this limits the static loading capacity of the structure, which may result to unsolvable problems, especially for vertical vibration isolation.

Figure 1.c presents the fundamental concept of the KDamper. Similarly to the QZS oscillator, it uses a negative stiffness element $k_{N}$. However, contrary to the QZS oscillator, the first basic requirement of the KDamper is that the overall static stiffness of the system is maintained:

$$
k_{R}+\frac{k_{P} k_{N}}{k_{P}+k_{N}}=k
$$

In this way, the KDamper can overcome the fundamental disadvantage of the QZS oscillator. Compared to the TMD damper, the KDamper uses an additional negative stiffness element $k_{N}$, which connects the additional mass also to the base. Thus, the equation of motion of the KDamper becomes:

$$
\begin{array}{r}
m \ddot{u}_{S}+c_{D}\left(\dot{u}_{S}-\dot{u}_{D}\right)+k_{R} u_{S}+k_{P}\left(u_{S}-u_{D}\right)=-m a_{G} \\
m_{D} \ddot{u}_{D}-c_{D}\left(\dot{u}_{S}-\dot{u}_{D}\right)-k_{P}\left(u_{S}-u_{D}\right)+k_{N} u_{D}=-m_{D} a_{G}
\end{array}
$$

or equivalently: 


$$
\begin{gathered}
m \ddot{u}_{S}+k_{R} u_{S}+m_{D} \ddot{u}_{D}+k_{N} u_{D}=-\left(m+m_{D}\right) a_{G} \\
m_{D} \ddot{u}_{D}-c_{D}\left(\dot{u}_{S}-\dot{u}_{D}\right)-k_{P}\left(u_{S}-u_{D}\right)+k_{N} u_{D}=-m_{D} a_{G}
\end{gathered}
$$

Assuming a harmonic excitation in the form of:

$$
a_{G}(t)=A_{G} \exp (j \omega t)
$$

and a steady state response of:

$$
\begin{aligned}
& u_{S}(t)=\widetilde{U}_{S} \exp (j \omega t) \\
& u_{D}(t)=\widetilde{U}_{D} \exp (j \omega t)
\end{aligned}
$$

the equations of motion (Eq. 4-5) of the TMD become:

$$
\begin{array}{r}
-\omega^{2} m \widetilde{U}_{S}+j \omega c_{D}\left(\widetilde{U}_{S}-\widetilde{U}_{D}\right)+k_{R} \widetilde{U}_{S}+k_{P}\left(\widetilde{U}_{S}-\widetilde{U}_{D}\right)=-m A_{G} \\
-\omega^{2} m_{D} \widetilde{U}_{D}-j \omega c_{D}\left(\widetilde{U}_{S}-\widetilde{U}_{D}\right)-k_{P}\left(\widetilde{U}_{S}-\widetilde{U}_{D}\right)+k_{N} \widetilde{U}_{D}=-m_{D} A_{G}
\end{array}
$$

or equivalently:

$$
\begin{gathered}
-\omega^{2} m \widetilde{U}_{S}+k_{R} \widetilde{U}_{S}-\omega^{2} m \widetilde{U}_{D}+k_{N} \widetilde{U}_{D}=-\left(m+m_{D}\right) A_{G} \\
-\omega^{2} m_{D} \widetilde{U}_{D}-j \omega c_{D}\left(\widetilde{U}_{S}-\widetilde{U}_{D}\right)-k_{P}\left(\widetilde{U}_{S}-\widetilde{U}_{D}\right)+k_{N} \widetilde{U}_{D}=-m_{D} A_{G}
\end{gathered}
$$

A careful examination of Eq. (11-12) reveals that the amplitude $F_{M D}$ of the inertia force of the additional mass and the amplitude $F_{N}$ of the negative stiffness force:

$$
\begin{gathered}
F_{M D}=-\omega^{2} m_{D} \widetilde{U}_{D} \\
F_{N}=k_{N} \widetilde{U}_{D} \leq 0
\end{gathered}
$$

are exactly in phase, due to the negative value of $k_{N}$. Thus, the KDamper essentially consists an indirect approach to increase the inertia effect of the additional mass $m_{D}$ without however increasing directly the mass $m_{D}$ itself. Moreover, it should be noticed that the value of $F_{M D}$ depends on the frequency, while the value of $F_{N}$ is constant in the entire frequency range, a fact which is of importance for low frequency vibration isolation.

\section{THEORY AND MODELING}

The wind turbine tower is modeled as an assemblage of beam elements with sway degrees of freedom considered to be the dynamic degrees of freedom. The theoretical development is based on the assumption that the cross-sectional dimension within the element remains the same, i.e. prismatic beam element. Additional assumptions made for the analytical formulation are: (i) the wind turbine tower is considered to remain within the elastic limit under the earthquake excitation and/or the aerodynamic loads; (ii) the system is subjected to a single horizontal (uni-directional) component of the earthquake ground motion; and (iii) the effects of soil-structure-interaction (SSI) are not taken into consideration.

\subsection{Mathematical modeling of wind turbine tower}

Figure 2(a-f) shows the lumped mass model of the wind turbine tower, placement of the TMDs and the KDamper and the degrees of freedom considered in the study. The governing equations of motion for the wind turbine tower installed with the STMD at the top and in- 
stalled with the d-TMDs and the KDamper are obtained by considering the equilibrium of forces at the location of each degree of freedom as follows.

$$
\begin{aligned}
& {\left[M_{S}\right]\left\{x_{S}\right\}+\left[C_{S}\right]\left\{x_{S}\right\}+\left[K_{S}\right]\left\{x_{S}\right\}=-\left[M_{S}\right]\{r\} \ddot{x}_{g}} \\
& {\left[M_{S}\right]\left\{x_{S}\right\}+\left[C_{S}\right]\left\{x_{S}\right\}+\left[K_{S}\right]\left\{x_{S}\right\}=[P]}
\end{aligned}
$$

where $\left[M_{S}\right],\left[C_{S}\right]$ and $\left[K_{S}\right]$ are the mass, damping, and stiffness matrices of the wind turbine tower, respectively of order $(N+n) \times(N+n)$. Here, $\mathrm{N}$ indicates degrees of freedom (DOF) for the wind turbine tower and $\mathrm{n}$ indicates DOF for the STMD, 2TMDs or KDamper. Further, $\left\{x_{S}\right\}=\left\{x_{1}, \mathrm{x}_{2}, \mathrm{x}_{3}, \ldots, \mathrm{x}_{N-1}, \mathrm{x}_{N}, \mathrm{X}_{1}, \ldots, \mathrm{X}_{n}\right\}^{T},\left\{x_{s}\right\}$ and $\left\{x_{s}\right\}$ are the unknown relative nodal displacement, velocity, and acceleration vectors, respectively. The earthquake ground acceleration is represented by $\ddot{x}_{g}$ and $\{r\}$ is the vector of influence coefficients. The modal frequencies and mode shapes of the wind turbine tower without control systems are determined by solving the Eigen value problem. A TMD is placed where the mode shape amplitude of the wind turbine tower is the largest/larger in a particular mode and is tuned to the corresponding modal frequency. Not more than one TMD is placed at a location, and the stiffness (ki) and damping (ci) parameters of the TMDs $(i=1 \ldots n)$ are calculated based on the modal frequencies. For the TMDs and the KDamper, the mass matrix is of order $(N+n) \times(N+n)$ as follows:

$$
\left[M_{S}\right]=\left[\begin{array}{ll}
{\left[M_{N}\right]_{N \times N}[0]_{n \times N}} \\
{[0]_{n \times N}} & {\left[m_{n}\right]_{n \times n}}
\end{array}\right]
$$

where $\left[M_{N}\right]_{N \times N}$ shows the mass matrix for the chimney and $\left[m_{n}\right]_{n \times n}$ indicates the mass matrix of the TMDs. In Eq. (17), for obtaining mass matrix corresponding to the STMD $n=1$ is considered. The condensed stiffness matrix $\left[K_{N}\right]_{N \times N}$ is corresponding to the sway degrees of freedom taken as the dynamic DOF. The damping matrix $\left[C_{N}\right]_{N \times N}$ is not explicitly known but is obtained with the help of the Rayleigh's approach using same damping ratio in all modes. The stiffness matrix, $\left[K_{N}\right]_{N \times N}$ and damping matrix, $\left[C_{N}\right]_{N \times N}$ are expressed corresponding to the degrees of freedom associated with the TMDs or the KDamper. For the wind turbine tower installed with the STMD, 2TMDs or KDamper stiffness and damping are inputs in the generic stiffness matrix $\left[K_{S}\right]$ and damping matrix $\left[C_{S}\right]$ as follows.

$$
\begin{gathered}
\left.\left[K_{S}\right]=\left[\begin{array}{ll}
{\left[K_{N}\right]_{N \times N}[0]_{N \times n}} \\
{[0]_{n \times N}} & {[0]_{n \times n}}
\end{array}\right]+\left[\begin{array}{ll}
{\left[K_{n}\right]_{N \times N}-\left[K_{n}\right]_{N \times n}} \\
-\left[K_{n}\right]_{n \times N} & {\left[K_{n}\right]_{n \times n}}
\end{array}\right]\right]_{(N+n) \times(N+n)} \\
\left.\left[C_{S}\right]=\left[\begin{array}{ll}
{\left[C_{N}\right]_{N \times N}[0]_{N \times n}} \\
{[0]_{n \times N}} & {[0]_{n \times n}}
\end{array}\right]+\left[\begin{array}{ll}
{\left[C_{n}\right]_{N \times N}-\left[C_{n}\right]_{N \times n}} \\
-\left[C_{n}\right]_{n \times N} & {\left[C_{n}\right]_{n \times n}}
\end{array}\right]\right]_{(N+n) \times(N+n)}
\end{gathered}
$$


The coupled differential equations of motion (Eq. (15-16)) for the wind turbine tower installed with TMD(s) or KDamper are thus derived and solved using Newmark's integration method.

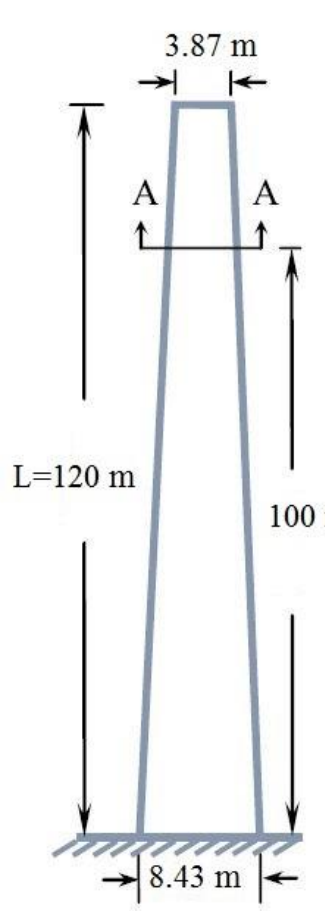

(a)

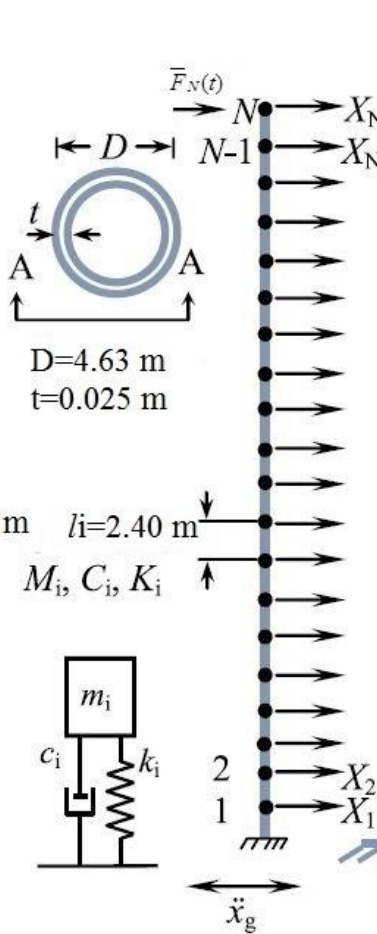

(b)

(c)
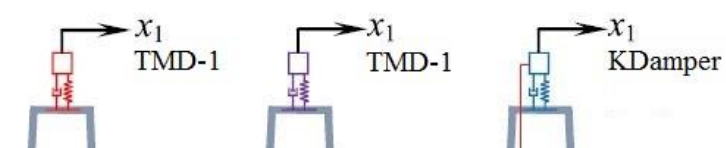

(d)

(e)

(e) TMD and section A-A, (c) lumped mass idealization for wind turbine tower installed with, (d) single TMD, (e) 2 TMDs, and (f) KDamper.

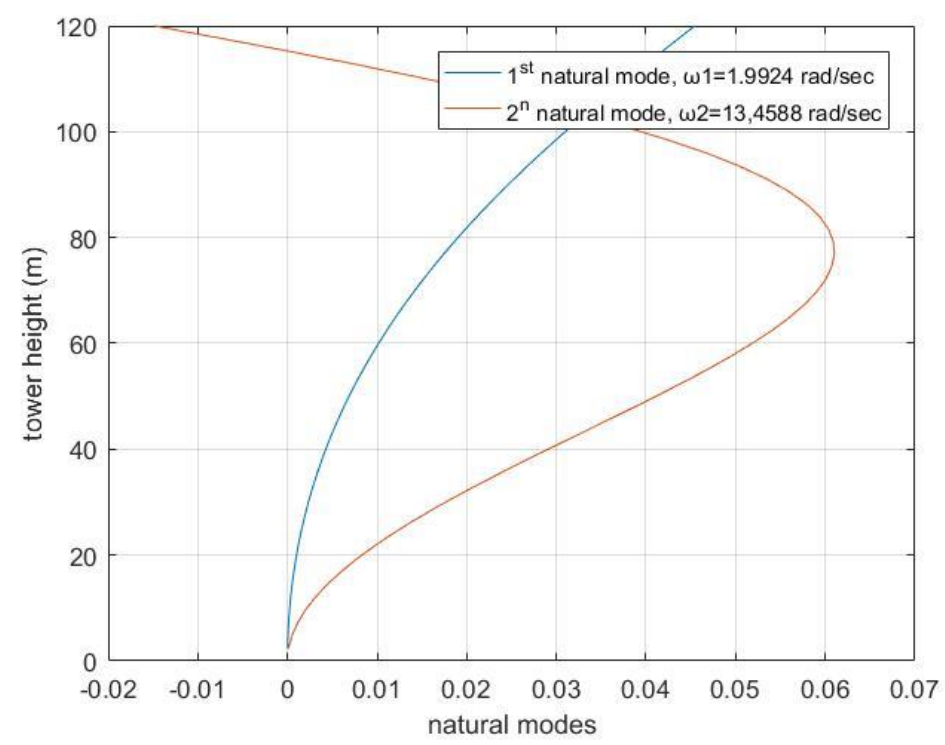

Figure 3: Modeshapes of wind turbine tower with fixed support. 


\subsection{Designing and placement of resonant dampers}

\section{Test case 1: Uncontrolled wind turbine tower.}

\section{Test case 2(a): Single TMD placed on top of wind turbine tower.}

The deciding criterion for the use of the single TMD is the control of the first modal response. The frequency of the TMD is calculated as

$$
f=\frac{\omega}{\Omega_{1}}
$$

Where the tuning frequency ratio is $f=1$. Here, $\omega$ and $\Omega_{1}$ respectively are the frequency of the TMD and the first natural frequency of the wind turbine tower before controlling. The effectiveness of the TMD installed on a wind turbine tower depends on mass ratio, $\mu=m_{t} / M_{t}$, where $m_{t}$ is the mass of the TMD, $M_{t}=\sum_{i=1}^{N} M_{i}$ is the mass of the wind turbine tower and $M_{i}$ are the lumped masses of the wind turbine tower.

The stiffness $k$ is used for adjusting the frequency of the TMD such that

$$
k=m \omega^{2}
$$

The damping $c$ of the TMD is calculated as follows

$$
c=2 \zeta_{D} m \omega
$$

where $\zeta_{D}$ is the damping ratio of the TMD.

\section{Test case 2(b): Pendulum placed at the top of wind turbine tower.}

The procedure is the same with the single TMD placed on top of wind turbine tower, with the difference for the calculation of the stiffness $K_{\text {pend }}$ (Eq. (23)).

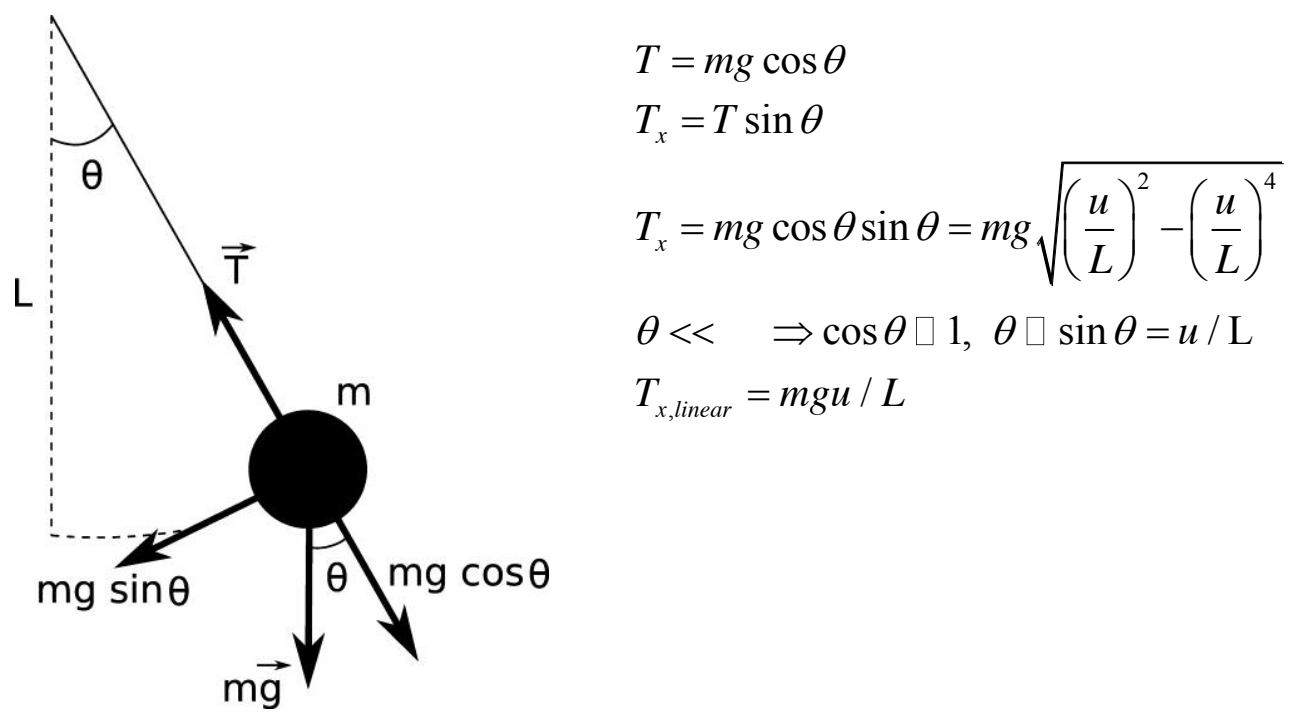

Figure 4: Simple Pendulum assuming linear behavior. 


$$
K_{p e n d}=\frac{\partial T_{x}}{\partial u}=m g / L
$$

\section{Test case 3: 2TMDs placed according to the 2 first modal shapes.}

This time the goal is to control the first 2 modal responses of the wind turbine tower. The frequency of each TMD is calculated as:

$$
f_{i}=\frac{\omega_{i}}{\Omega_{i}} \quad \mathrm{i}=1,2
$$

where all $(\mathrm{i}=1,2)$ tuning frequency ratios are, $f_{i}=1$. Here, $\omega_{i}$ and $\Omega_{i}$ respectively are the frequencies of the TMD and natural frequencies of the wind turbine tower before controlling. The effectiveness of the TMD installed on a chimney depends on mass ratio, $\mu=m_{t} / M_{t}$, where $m_{t}=\sum_{i=1}^{2} m_{i}$ is te total mass of the TMDs, $M_{t}=\sum_{i=1}^{N} M_{i}$ is the mass of the wind turbine tower, $m_{i}$ and $M_{i}$ are the lumped masses of the TMDs and wind turbine tower, respectively. Thus, the mass of the TMDs is calculated by $m_{t}=\mu M_{t}$. The masses of the TMDs, $m_{i}=\operatorname{diag}\left(m_{1}, m_{2}\right)$ are taken equal. Mass $\left(m_{i}\right)$ used for each TMD unit is calculated as follows.

$$
m_{i}=\frac{m_{t}}{2} \quad \mathrm{i}=1,2
$$

The stiffness (ki) is used for adjusting the frequency of each TMD unit such that

$$
k_{i}=m_{i} \omega_{t}^{2} \quad \mathrm{i}=1,2
$$

The damping ratio $\left(\zeta_{D}=\zeta_{1}=\zeta_{2}\right)$ of the TMDs is kept the same and the damping $\left(\mathrm{c}_{i}\right)$ of the TMDs is calculated as follows.

$$
c_{i}=2 \zeta_{D} m_{i} \omega_{i} \quad \mathrm{i}=1,2
$$

\section{Test case 4: Single KDamper placed on top of the wind turbine tower.}

The optimal design approach for the parameters of the KDamper controlling a single degree of freedom system, follows exactly the corresponding steps as in Den Hartog (1956). The first step is for the user to define the parameters $\mu$ and $\kappa$ as follows:

$$
\begin{aligned}
& \mu=m_{D} / m_{s} \\
& \kappa=-\frac{k_{N}}{k_{e}+k_{N}}
\end{aligned}
$$

where $m_{s}$ is the system's mass and $m_{D}$ is the additional mass of the KDamper, as shown in Figure 1.c. The mass ratio $\mu$, is selected arbitrarily. The bigger the value of $\mu$ and consequently the value of $m_{D}$, the better the results of the system's response. However, when applying to structures where the value of $m_{s}$ is extremely big, an optimal choice between the desired effects on structure's response and the ability to construct the device should be found.

In terms of the parameter $\kappa$, further explanation on how to choose the right value is given later in this paper. Once $\mu$ and $\kappa$ are chosen, frequency ratio $\rho$ is defined as 


$$
\begin{gathered}
\rho=\omega_{D} / \omega_{o} \\
\omega_{o}=\sqrt{k_{o} / m_{s}} \\
\omega_{D}=\sqrt{k_{D} / m_{D}}
\end{gathered}
$$

where $k_{D}$ is equal to $k_{e}+k_{N}$ for the KDamper.

For each set of the parameters $\mu, \kappa$ the optimum value of $\rho$ is

$$
\rho(\kappa, \mu)=\sqrt{-C_{\rho} / B_{\rho}}
$$

Coefficients $C_{\rho}$ and $B_{\rho}$ are calculated according to Table 1 and Equations (34-37).

\begin{tabular}{llllllll}
\hline & $\mathrm{A} 2 \mathrm{i}$ & $\mathrm{A} 0 \mathrm{i}$ & $\mathrm{B} 0 \mathrm{i}$ & $\mathrm{C} 2 \mathrm{i}$ & $\mathrm{C} 0 \mathrm{i}$ & $\mathrm{D} 2 \mathrm{i}$ & $\mathrm{D} 0 \mathrm{i}$ \\
\hline $\mathrm{i}=\rho$ & 0 & $1+(1+\kappa) \mu$ & 0 & $-\left[1+(1+\kappa)^{2} \mu\right]$ & 0 & 0 & $\kappa^{2} \mu$ \\
$\mathrm{i}=\rho$ & -1 & 0 & $1+\mu$ & -1 & -1 & $-(1+\mu)$ & 1 \\
\hline
\end{tabular}

Table 1: Values of coefficients $A_{r i}, B_{r i}, C_{r i}$ and $D_{r i}$ for $r=2$ or 0 .

$$
\begin{gathered}
B_{\rho A}=\left[\left(A_{0 \rho} D_{20}+D_{2 \rho} A_{00}\right)+\left(A_{2 \rho} D_{00}+D_{0 \rho} A_{20}\right)+\left(B_{0 \rho} C_{20}+C_{2 \rho} B_{00}\right)\right] D_{20} \\
B_{\rho B}=-2\left(A_{2 \rho} D_{20}+A_{20} D_{2 \rho}+B_{0 \rho}\right) D_{00}-2\left(A_{20} D_{20}+B_{00}\right) D_{0 \rho} \\
B_{\rho}=B_{\rho A}+B_{\rho B} \\
C \rho=\left(A_{00} D_{20}+A_{20} D_{00}+B_{00} C_{20}\right) D_{20}-2\left(A_{20} D_{20}+B_{00}\right) D_{00}
\end{gathered}
$$

Consequently, the values of the KDamper's parameters finally result as:

$$
\begin{gathered}
\frac{k_{N}}{k_{o}}=\kappa_{N}=-\kappa \mu \rho^{2} \\
\frac{k_{e}}{k_{o}}=\kappa_{e}=(1+\kappa) \mu \rho^{2} \\
\frac{k_{R}}{k_{o}}=\kappa_{R}=1+\kappa(1+\kappa) \mu \rho^{2} \\
m_{D}=\mu m_{s} \\
c_{D}=2 \zeta_{D} \sqrt{\left(k_{e}+k_{N}\right) m_{D}}
\end{gathered}
$$

The increase of the value of $\kappa$ is upper limited by a value of $\kappa_{\max }$. As it is observed in Figure 5.a, when $\kappa$ reaches $\kappa_{\max }$ the frequency ratio $\rho$ tends to infinity. However, increasing $\kappa$ has a number of implications in the design of the KDamper. First, high stiffness values result, as presented in Figure 6. 
(a)

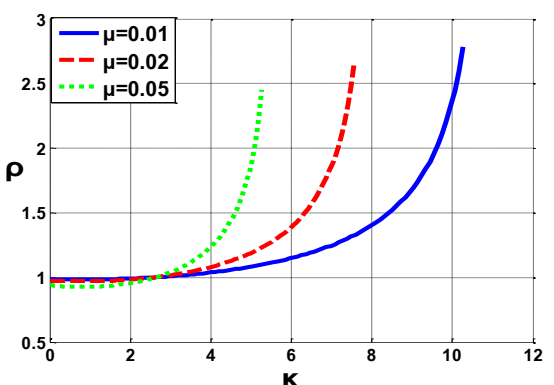

(b)

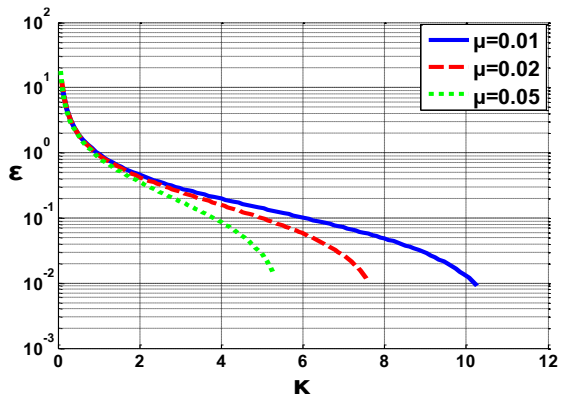

Figure 5: Variation of the $\kappa$ and $\mu$ KDamper parameters. (a) on the value of $\rho=\omega_{D} / \omega_{o}$. (b) on the static stability margin $\varepsilon$.

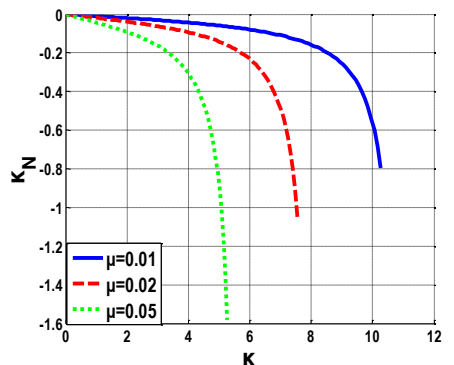

(a)

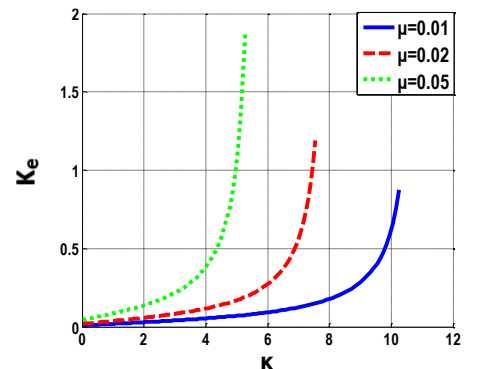

(b)

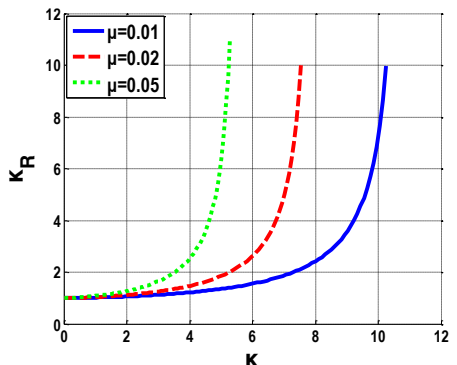

(c)

Figure 6: Increase of the values of KDamper's stiffness elements by increasing $\kappa$. (a) $\kappa_{N}$, (b) $\kappa_{e}$, (c) $\kappa_{R}$.

Moreover, increasing the stiffness and especially $k_{N}$, may endanger the static stability of the system. Although $k_{N}$ is selected according to Eq. (29) to ensure the static stability, variations of $k_{N}$ result in practice due to various reasons, such as temperature variations, manufacturing tolerances, or non-linear behavior, since almost all negative stiffness designs result from unstable non-linear systems. Consequently, an increase of the absolute value of $k_{N}$ by a factor $\varepsilon$ may lead to a new value of $k_{N L}$ where the structure becomes unstable.

$$
k_{R}+\frac{k_{e} k_{N L}}{k_{e}+k_{N L}}=0 \Leftrightarrow k_{N L}=-\frac{k_{R} k_{e}}{k_{R}+k_{e}}=(1+\varepsilon) k_{N}
$$

Substitution of Eq. $(38,39,40)$ into Eq. (43) leads to the following estimate for the static stability margin $\varepsilon$

$$
\varepsilon=\frac{1}{\kappa\left[1+(1+\kappa)^{2} \mu \rho^{2}\right]}
$$

Figure 5.b presents the variation of $\varepsilon$ over $\kappa$ and $\mu$. As it can be observed from Eq. (44) and Figure 5.b, the increase of the negative stiffness of the system is upper bounded by the static stability limit of the structure, where $\varepsilon$ tends to zero. In practice, the value of $\kappa_{\max }$ can be calculated by a Goal Seek command with the condition that $\varepsilon$ is equal to zero. In this paper due to the fact that the system does not consist of a single degree of freedom, the parameters of the KDamper are calculated numerically. 


\section{NUMERICAL STUDY ON WIND TURBINE TOWER}

A wind turbine tower of variable tubular cross section $\left(E=2.1 \times 10^{8} \mathrm{kN} / \mathrm{m}^{2}\right.$, $\left.\rho=8.5 \mathrm{th} / \mathrm{m}^{3}, v=0.3, G=8.0769 \times 10^{7} \mathrm{kN} / \mathrm{m}^{2}, l=120 \mathrm{~m}\right)$ supporting the NREL baseline 5-MW nacelle and rotor (3 blades of length $r_{b l}=61.5 \mathrm{~m}$ ) [18] is examined. The radius and the thickness of the tubular cross section vary linearly along the tower length according to the dimensions. In order to take into account the inertial forces applied by the mechanical parts (nacelle, rotor and blades), an additional concentrated mass $m_{\text {top }}=403.22 \mathrm{tn}$ [18] is added at the top of the tower. The tower is considered to be clamped at its base and is subjected to the seismic excitations of JMA(1995) and TABAS and to the time-dependent horizontal force $\bar{F}_{N}(t)$ at its top due to the wind.

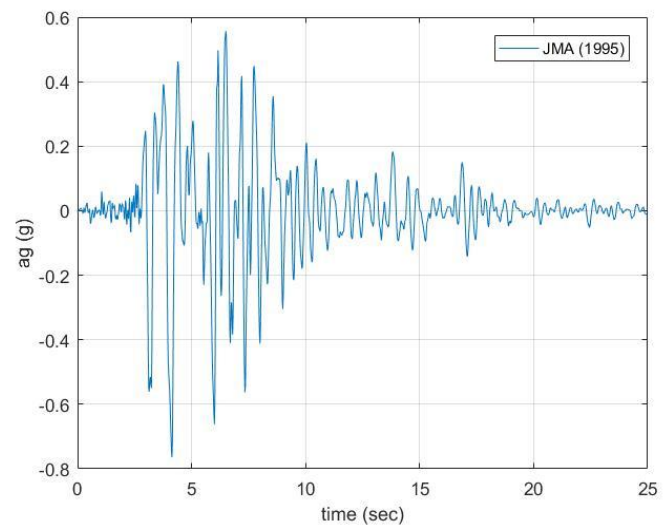

(a)

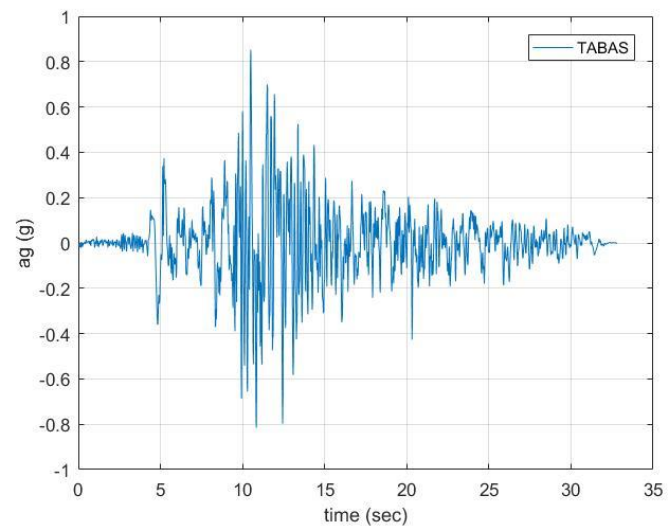

(b)

Figure 7: JMA(1995) (a) and TABAS (b) excitation motion accelerograms.

Moreover, the force $\bar{F}_{N}(t)$ can be obtained by the following relation

$$
F_{N}(\mathrm{r}, \mathrm{t})=\frac{1}{2} \rho_{a i r} C_{N}(r) c_{b l}(r)(\bar{V}(t))^{2}
$$

where $\rho_{\text {air }}=1.225 \times 10^{-3} \mathrm{tn} / \mathrm{m}^{3}$ is the air density and $C_{N}(r)$ is the coefficient computed by the corresponding lift $C_{L}(r)$ and drag $C_{D}(r)$ coefficients. The values of the latter coefficients depend on the airfoil characteristics of the blades and their distribution with respect to the "angle of attack" of the wind velocity $\bar{V}(t)$ vector passing through the blade profile can be retrieved from [12]. It is noted that $\bar{V}(t)$ is assumed to have a uniform spatial distribution over the actuator disc. $c_{b l}(r)$ is the chord of the blade profile varying along the blade length $r$, the distribution of which is obtained from [18],[12]. In order to evaluate $C_{N}(r)$, the classical Blade Element Momentum theory [9] is employed with an assumption of constant angular velocity of the blades $\Omega_{b l}=12.1 \mathrm{rpm}$ [12]. Subsequently, breaking $\bar{V}(t)$ down into a mean component $V_{m}$ and a fluctuating component $V(t)$, the corresponding mean and fluctuating components of $\bar{F}_{N}(t)$ can be obtained as

$$
F_{N m}=\frac{1}{2} \rho_{a i r} C_{N}(r) c_{b l}(r) V_{m}^{2}
$$




$$
F_{N}(r, t)=\frac{1}{2} \rho_{a i r} C_{N}(r) c_{b l}(r)\left(2 V_{m} V(t)+V(t)^{2}\right)
$$

In this application the mean velocity is $V_{m}=27 \mathrm{~m} / \mathrm{sec}$.Moreover, in order to take into account the wind velocity fluctuation at the altitude of $l=120 \mathrm{~m}$, an artificial velocity time history is generated following the regulations of EC1, part1.4 [3] and applying the procedure presented in [21] with a standard deviation $\sigma=3.3 \mathrm{~m} / \mathrm{sec}$. After having established $F_{N}(\mathrm{r}, \mathrm{t})$, the total concentrated force exerted on the top of the tower can be computed as

$$
\bar{F}_{N}(t)=3 \int_{0}^{r_{b l}} F_{N}(r, t) d r
$$

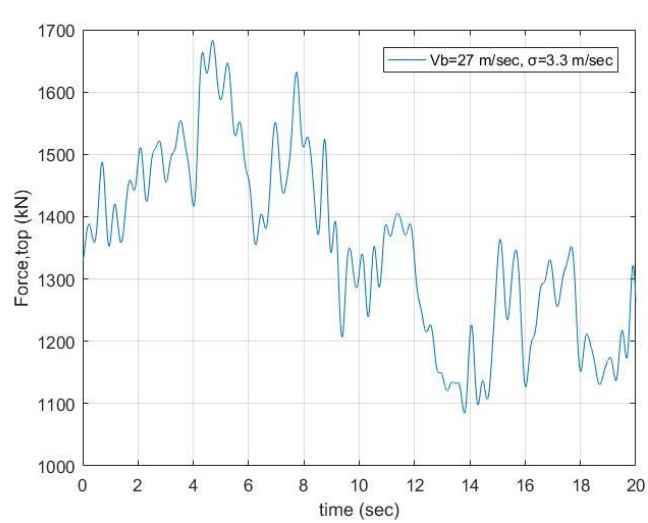

(a)

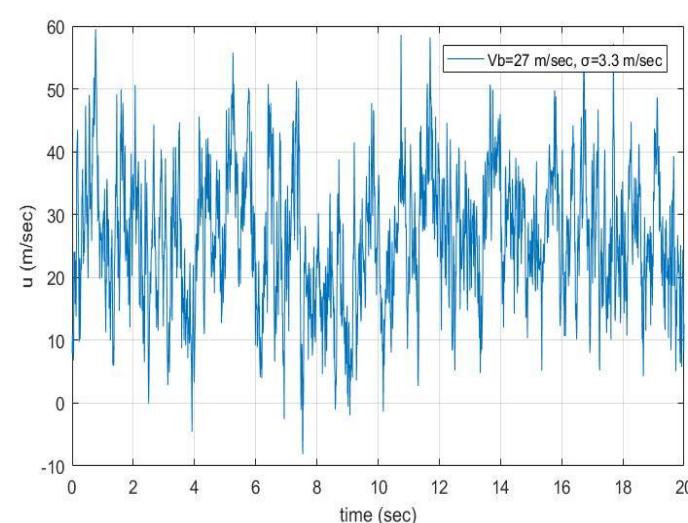

(b)

Figure 8: (a) Time history of the total Force $\bar{F}_{N}(t)$ applied at the top of the tower and (b) basic velocity $V_{b}$ at the altitude of $10 \mathrm{~m}$.

\subsection{Numerical results}

\section{Test case 1: uncontrolled wind turbine tower}

The critical factor for the design of the wind turbine is the deflection at the top of the wind turbine tower. In Figure 9 are presented the transfer functions for the displacement at the top of the wind turbine tower for base excitation and input force at the top of the tower respectively.

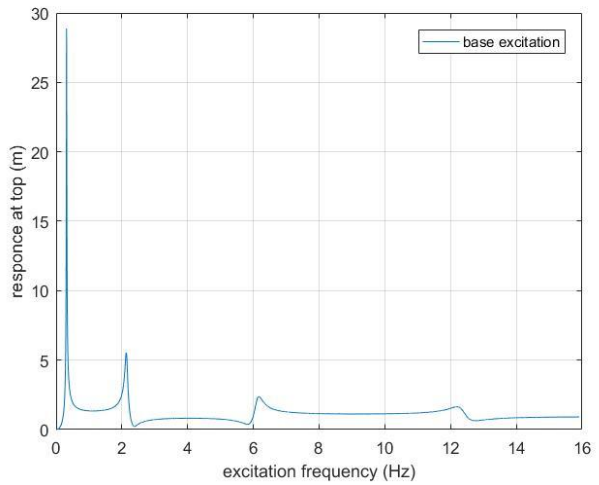

(a)

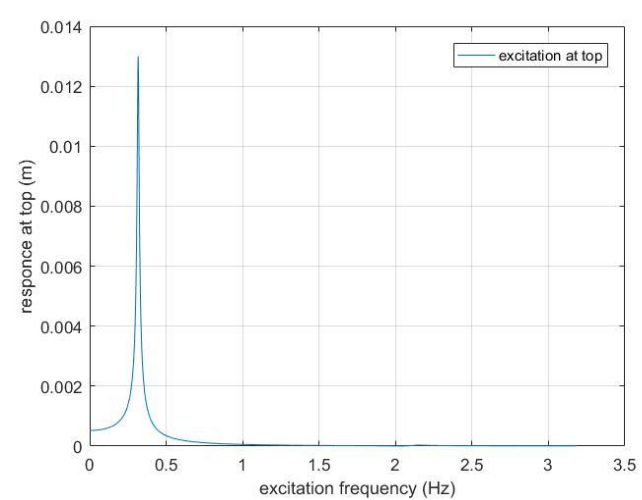

(b)

Figure 9: Transfer function for the displacement at the top of the wind turbine tower due to (a) base excitation, and (b) excitation at top. 
The Fourier transformations for the seismic excitation of JMA (1995) and TABAS and for the time-dependent horizontal force $\bar{F}_{N}(t)$ at its top due to the wind, are formulated so the main frequencies that are applied to the wind turbine can be determined.

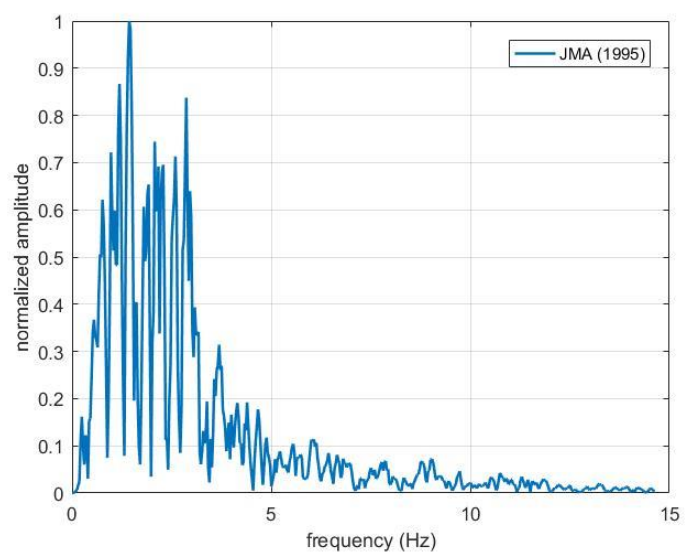

(a)

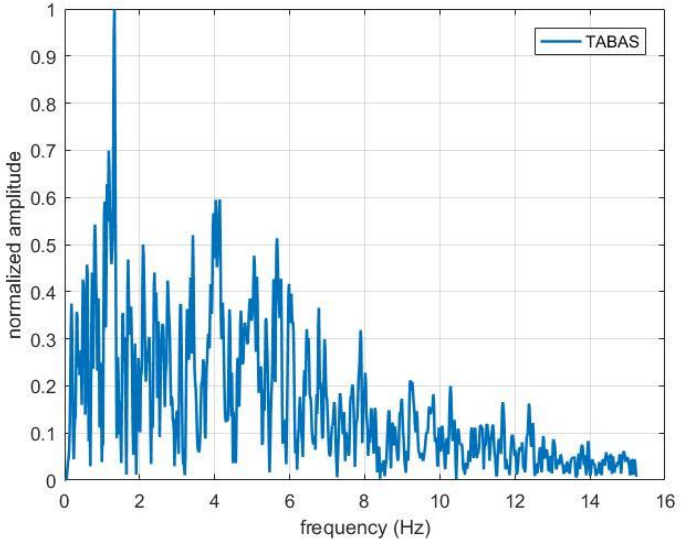

(b)

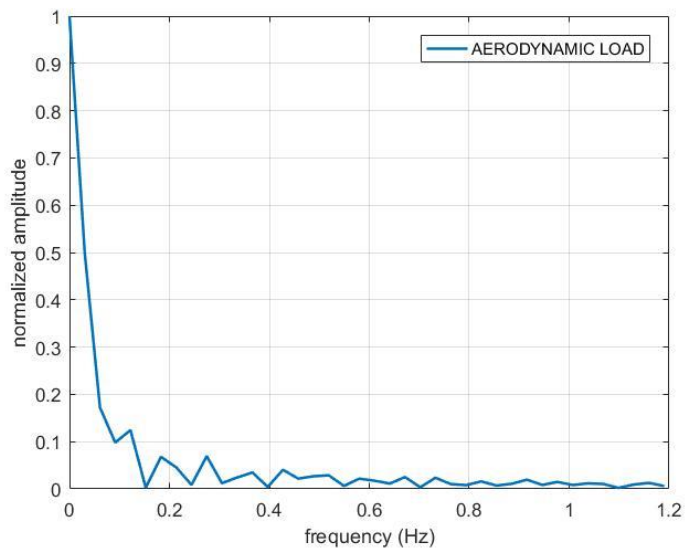

(c)

Figure 10: Fourier Transformation for (a) the seismic excitation of JMA (1995), (b) the seismic excitation of TABAS, and (c) for the time-dependent horizontal force $\bar{F}_{N}(t)$.

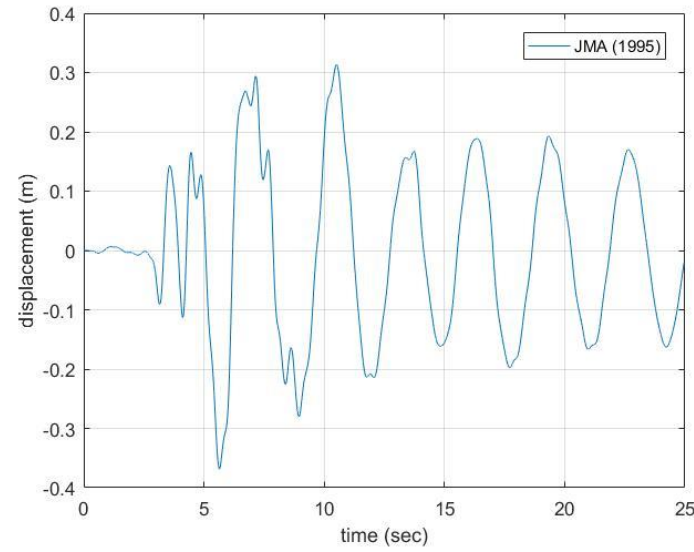

(a)

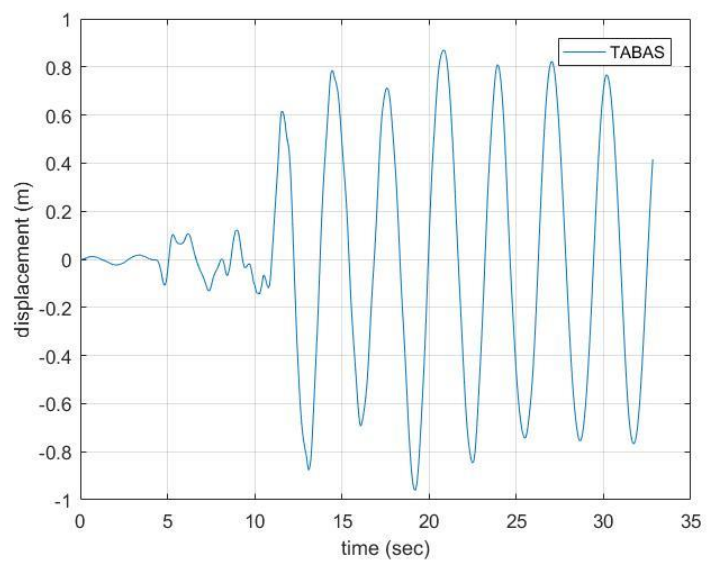

(b) 


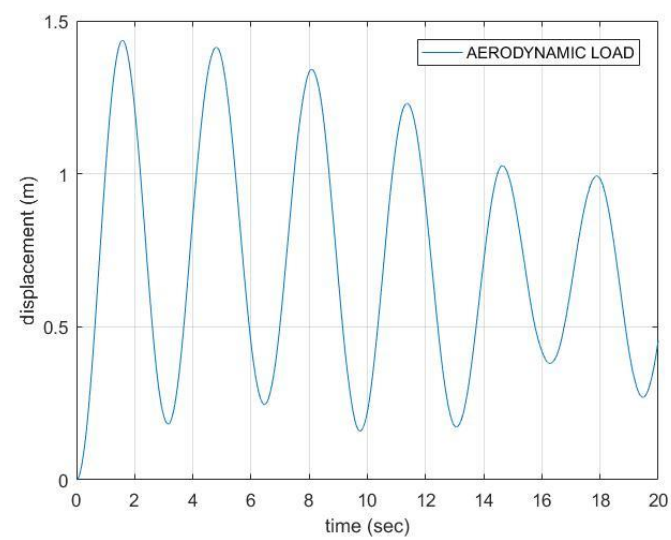

(c)

Figure 11: Dynamic response of the top of the wind turbine tower, displacement in (m), for (a) JMA (1995) seismic excitation $\left(\max \left|u_{\text {top }}\right|=0.3682 \mathrm{~m}\right)$, (b) TABAS seismic excitation $\left(\max \left|u_{\text {top }}\right|=0.9607 \mathrm{~m}\right)$ and (c) the force $\bar{F}_{N}(t)$ due to the wind $\left(\max \left|u_{t o p}\right|=1.436 \mathrm{~m}\right)$.

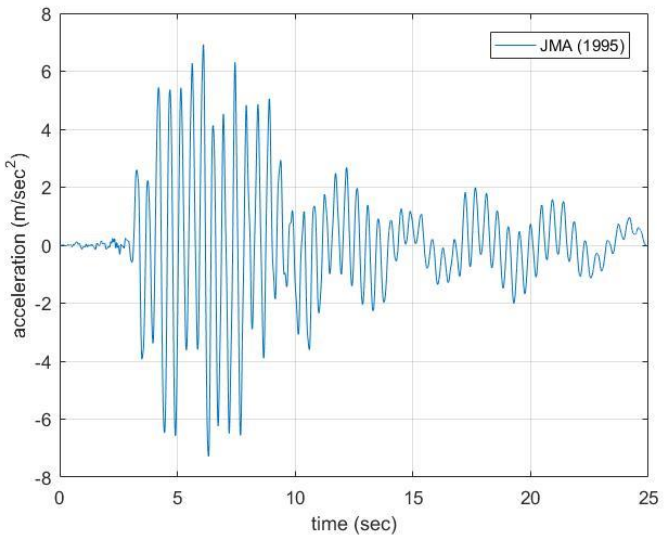

(a)

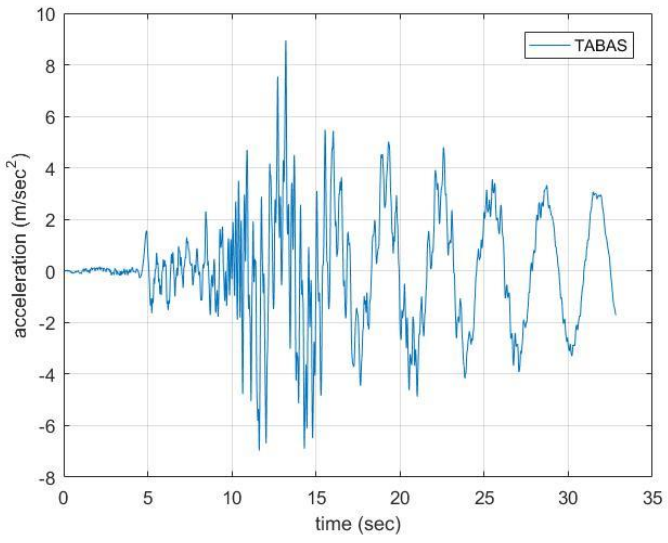

(b)

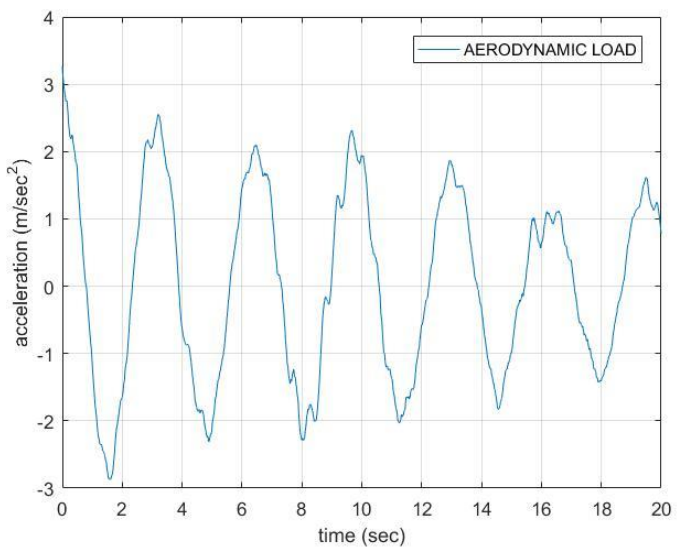

(c)

Figure 12: Dynamic response of the top of the wind turbine tower, acceleration in $\left(\mathrm{m} / \mathrm{sec}^{2}\right)$, for (a) JMA (1995) seismic excitation $\left(\max \left|a_{\text {top }}\right|=7.2802 \mathrm{~m} / \mathrm{sec}^{2}\right)$, (b) TABAS seismic excitation $\left(\max \left|a_{\text {top }}\right|=8.9502 \mathrm{~m} / \mathrm{sec}^{2}\right)$ and (c) the force $\bar{F}_{N}(t)$ due to the wind $\left(\max \left|a_{\text {top }}\right|=3.2665 \mathrm{~m} / \mathrm{sec}^{2}\right)$. 


\section{Test case 2: Single TMD placed on top of wind turbine tower - linear pendulum}

Given that the TMD is tuned with the first natural frequency before control, the only parameter of the TMD is the mass ratio $\mu$, the damping ratio is taken $\zeta=15 \%$.

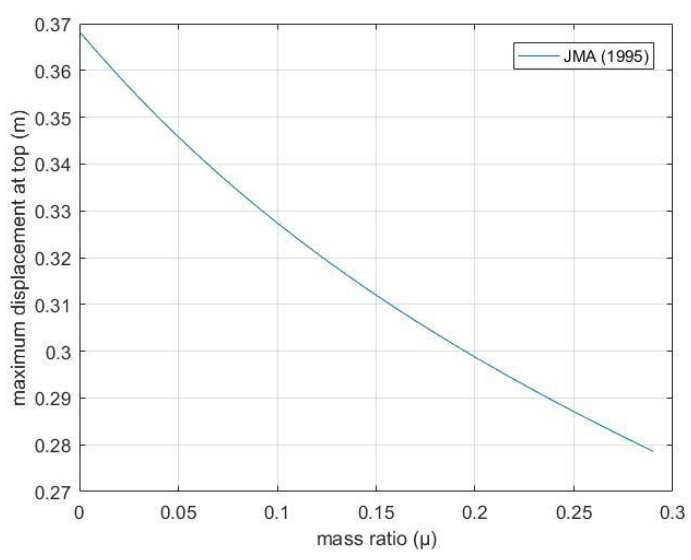

(a)

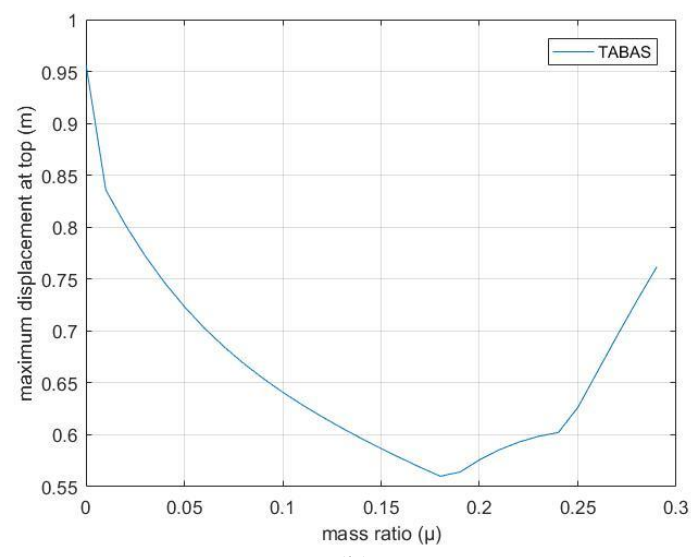

(b)

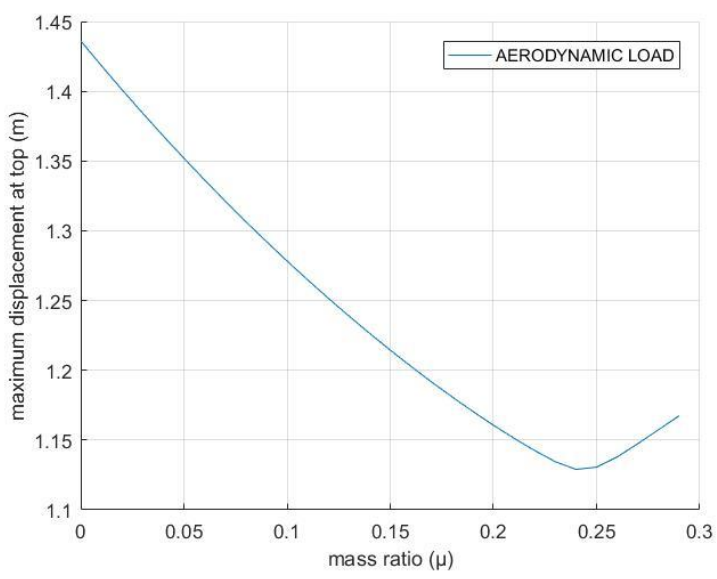

(c)

Figure 13: Variation of the maximum displacement at the top of the wind turbine tower on the mass ratio $\mu$ for (a) seismic excitation of JMA (1995), (b) seismic excitation of TABAS, and (c) the force $\bar{F}_{N}(t)$ due to the wind.

For each of these excitations a verification is made, in order to verify that the tuning of the TMD with the first natural frequency is optimum. A constant mass ratio of $10 \%$ and a damping ratio of $15 \%$ are taken and the only parameter is $\mathrm{Kd}$. Figure 14 shows the maximum displacement at the top of the wind turbine tower in relation to $\mathrm{Kd}$. 


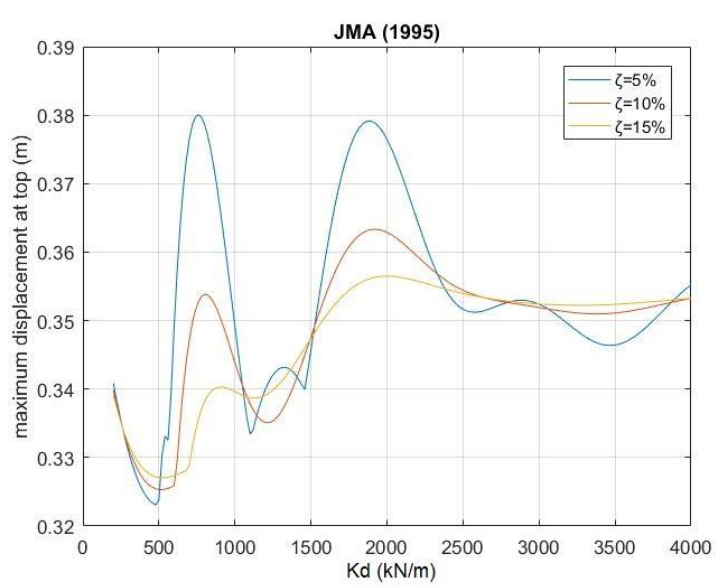

(a)

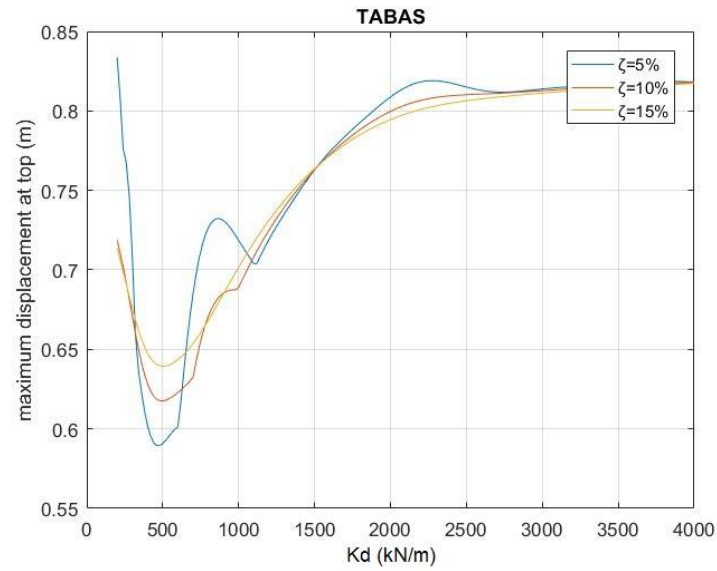

(b)

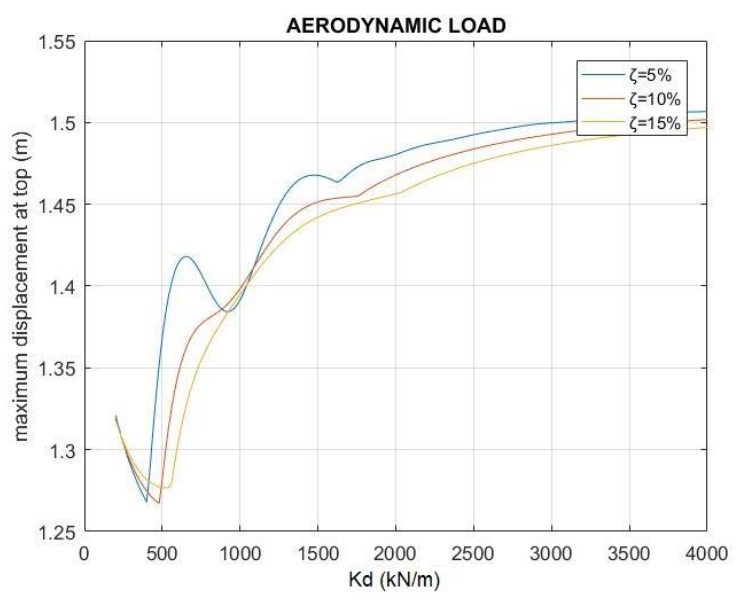

(c)

Figure 14: Variation of the maximum displacement at the top of the wind turbine tower on the stiffness $k$ of the TMD.

Given that $\omega_{1}=1.9924 \mathrm{rad} / \mathrm{sec}$ the expected value for $k$ is $k=\mu M_{t} \omega_{1}^{2}=454.3 \mathrm{kN} / \mathrm{m}$.It is observed that the minimum displacement of the top is around the value $450 \mathrm{kN} / \mathrm{m}$.

Figure 15 showns the Transfer function for the wind turbine tower controlled with a TMD with a mass ratio of $10 \%$ and a damping ratio of $15 \%$.

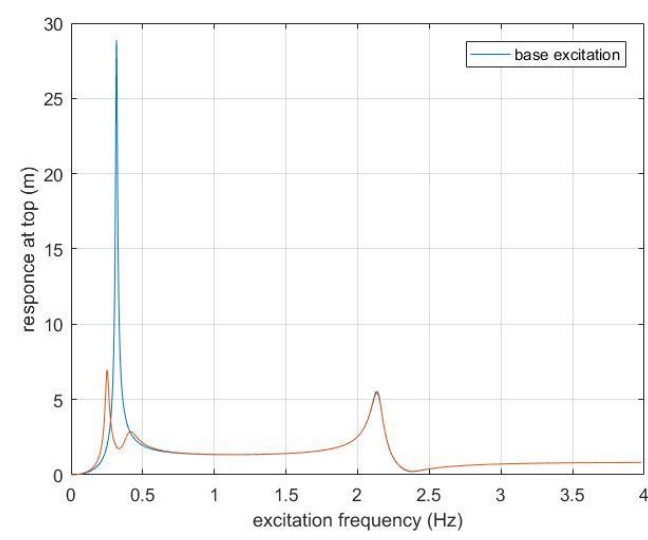

(a)

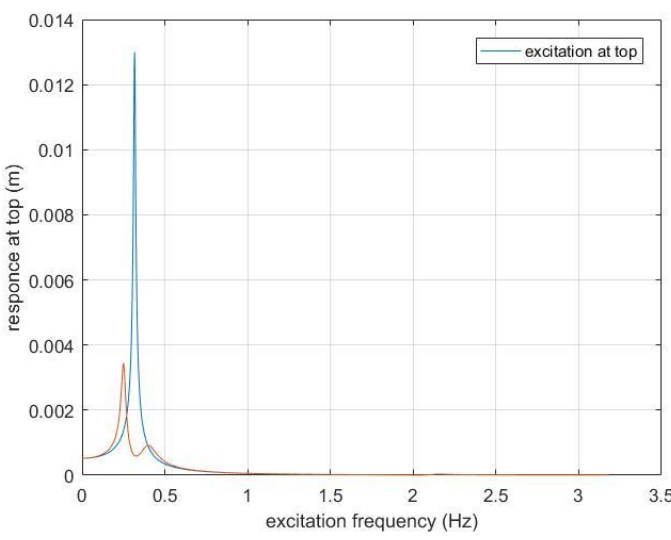

(b)

Figure 15: Transfer function for the displacement at the top of the wind turbine tower, controlled with a TMD, due to (a) base excitation, and (b) excitation at top 
Furthermore, a critical factor for the design of the wind turbine tower controlled with a TMD, is the relative displacement between the TMD and the top of the wind turbine tower for constructional reasons. The maximum displacement that the TMD can have, is $3,87 / 2=1.935$ m.

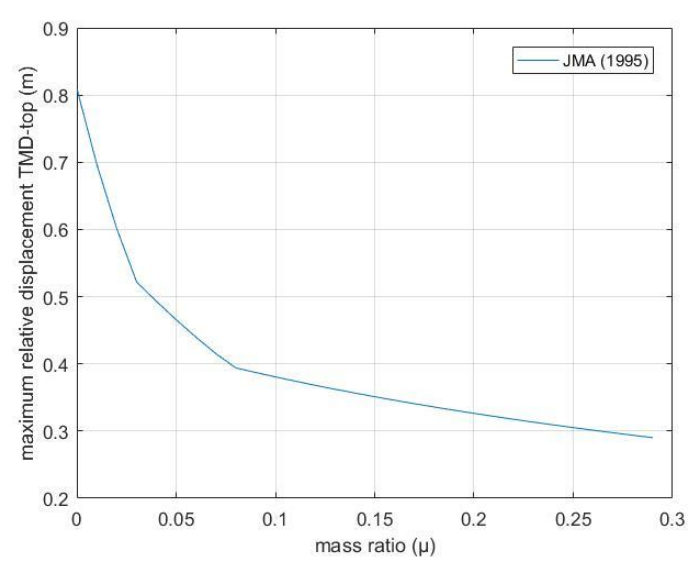

(a)

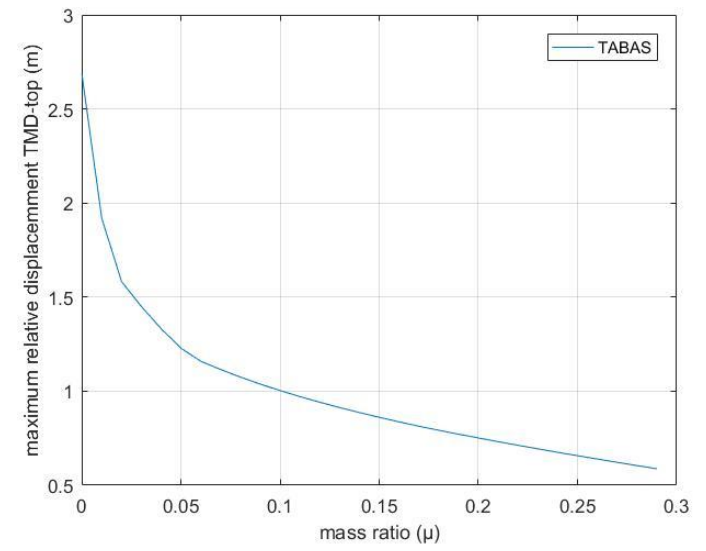

(b)

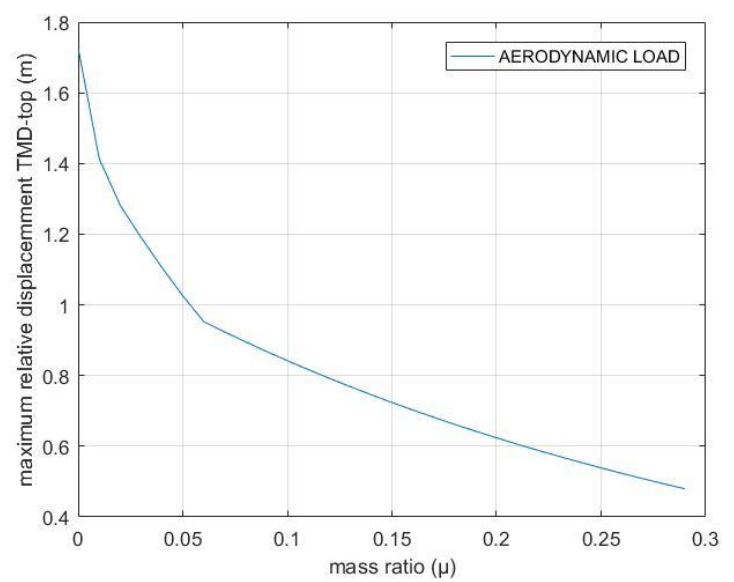

(c)

Figure 16: Variation of the maximum relative displacement of the TMD and the top of the wind turbine tower on the mass ratio $\mu$.

In Table 2 are presented the optimum results after the implementation of a tuned TMD with a mass ratio of $10 \%$ and a damping ratio of $15 \%$.

\begin{tabular}{llll}
\hline Excitation & $\max \left|u_{\text {top }}\right|(m)$ & $\max \left|a_{\text {top }}\right|\left(\mathrm{m} / \mathrm{sec}^{2}\right)$ & $\max \left|u_{\text {relativeTMD }}\right|(m)$ \\
\hline JMA (1995) & 0.3273 & 11.9731 & 0.3807 \\
TABAS & 0.6408 & 11.7115 & 1.0029 \\
$\bar{F}_{N}(t)$ & 1.2783 & 3.2665 & 0.8421 \\
\hline
\end{tabular}

Table 2: Results after the implementation of a TMD of a mass ratio of $10 \%$ and a damping ratio of $15 \%$.

The implementation of the TMD leads to a new system with reduced displacements along the tower of the wind turbine and higher damping ratio. In order to calculate the exact value of the new damping ratio, the isolated system is subjected to a free vibration with initial conditions, which in this case are according to the first modal eigenform of the wind turbine tower before control with the initial condition of the TMD equal to the initial condition at the top 
of the wind turbine tower. More specifically, the value of the new damping ratio is calculated as:

$$
\ln \left[\frac{u_{t o p}(t)}{u_{t o p}(t+T)}\right]=\frac{2 \pi \zeta}{\sqrt{1-\zeta^{2}}}
$$

where $T$ is the time between two consecutive peaks of the dynamic response of the system, as shown in Figure 17. The new damping ratio of the system equals to $15.68 \%$.

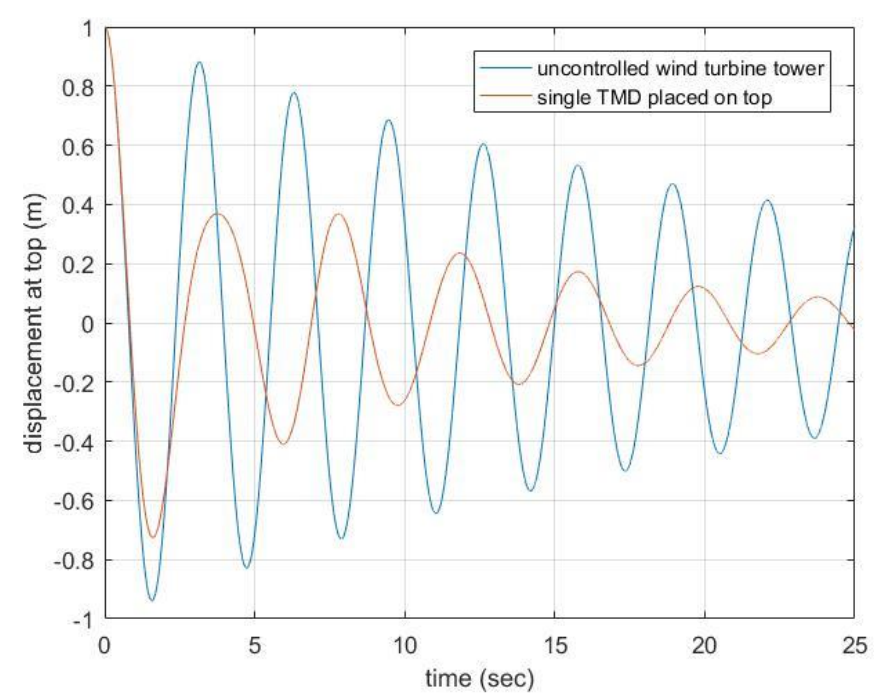

Figure 17: Dynamic response of the isolated system, with the TMD, to a free vibration with initial conditions.

\section{Test case 3: 2 TMDs placed according to the 2 first modal shapes}

Following the procedure that is presented in 3.2 the unknown parameter is the mass ratio $\mu$, the damping ratio $\zeta$ is taken $15 \%$. Again, beside the maximum displacement at the top of the wind turbine tower, a critical factor for the design of the wind turbine tower controlled with 2TMDs, is the relative displacements between the TMDs and the degree of freedom of the wind turbine tower that is relative with the respective TMD, for constructional reasons. The maximum displacement that can have a TMD is $3,87 / 2=1.935 \mathrm{~m}$.

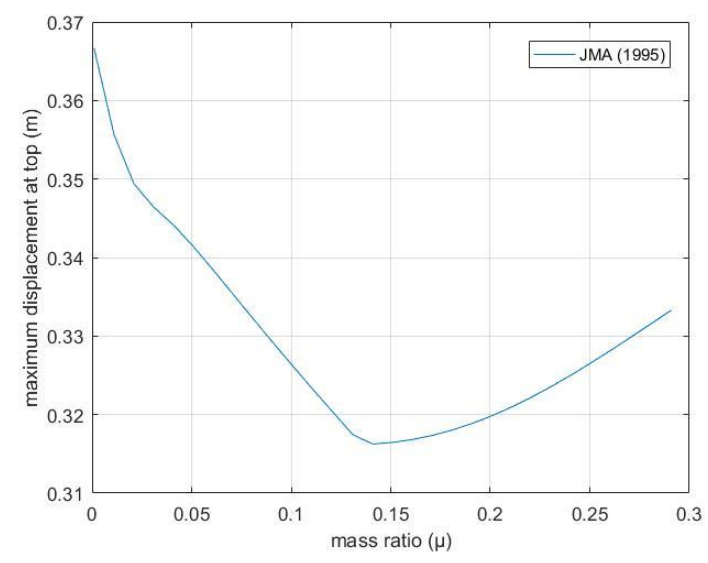

(a)

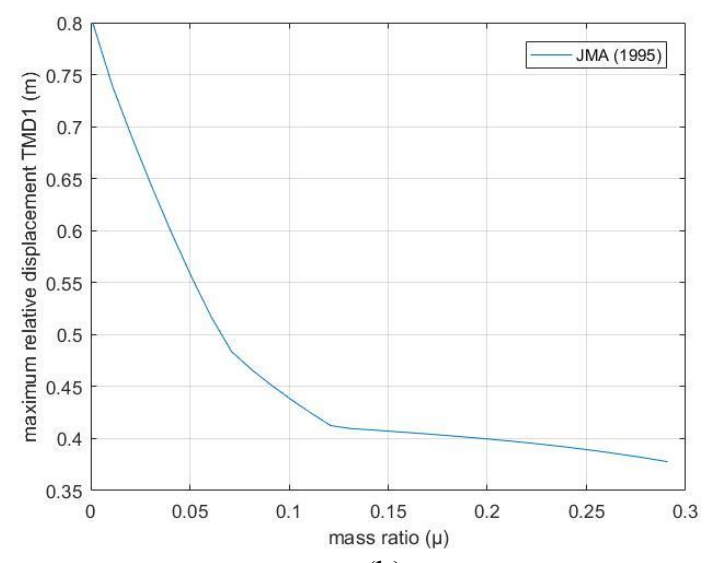

(b) 


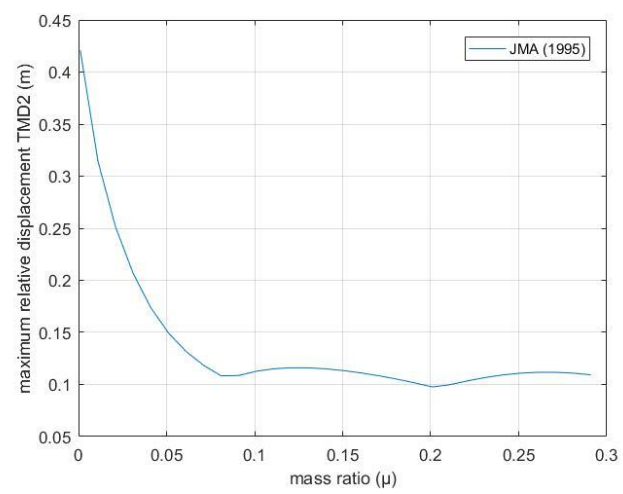

(c)

Figure 18: Variation of (a) the maximum displacement at the top of the wind turbine tower, (b) the maximum relative displacement of the TMD1, and (c) the maximum relative displacement of the TMD2 on the mass ratio $\mu$ for the seismic excitation of JMA (1995).

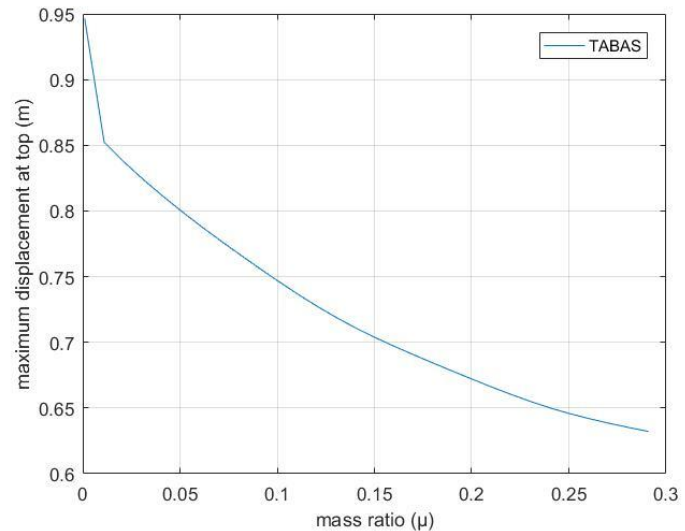

(a)

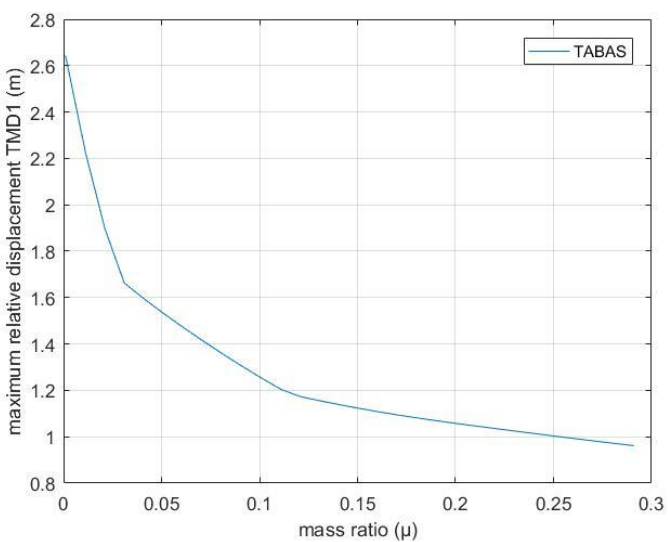

(b)

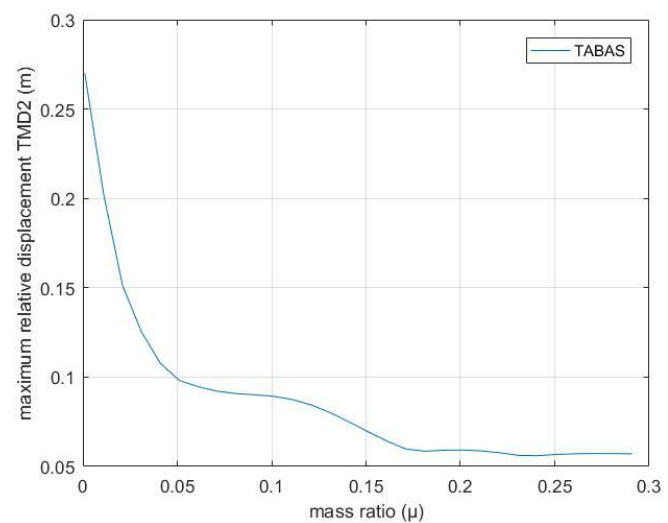

(c)

Figure 19: Variation of (a) the maximum displacement at the top of the wind turbine tower, (b) the maximum relative displacement of the TMD1, and (c) the maximum relative displacement of the TMD2 on the mass ratio $\mu$ for the seismic excitation of TABAS. 


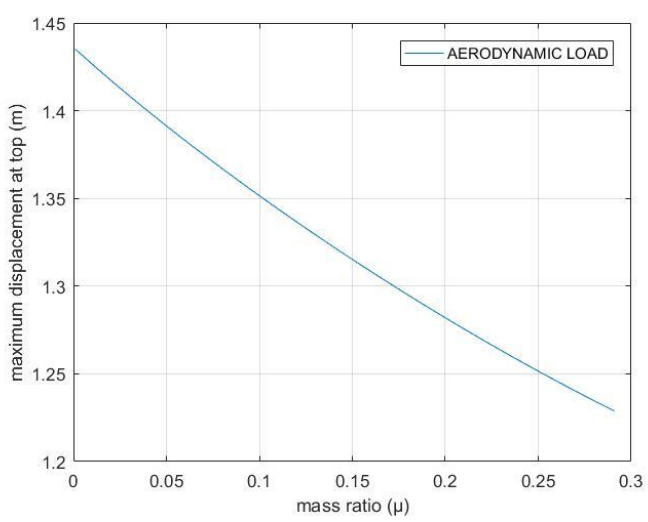

(a)

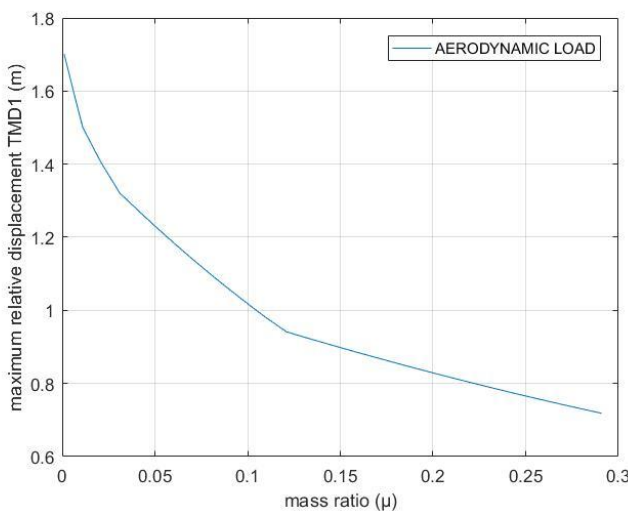

(b)

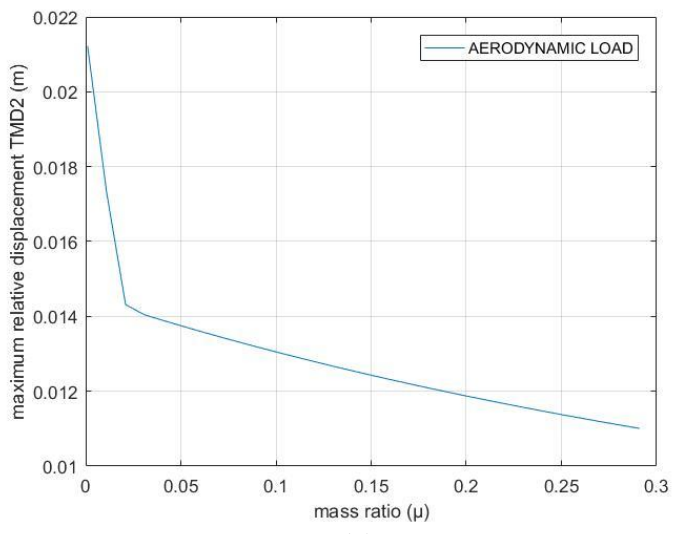

(c)

Figure 20: Variation of (a) the maximum displacement at the top of the wind turbine tower, (b) the maximum relative displacement of the TMD1, and (c) the maximum relative displacement of the TMD2 on the mass ratio $\mu$ for the force $\bar{F}_{N}(t)$ due to the wind.

In Figure 21 is shown the Transfer function for the wind turbine tower with 2TMDs controlling the first 2 natural frequencies of the wind turbine tower before control, with a mass ratio of $10 \%$ and a damping ratio of $15 \%$.

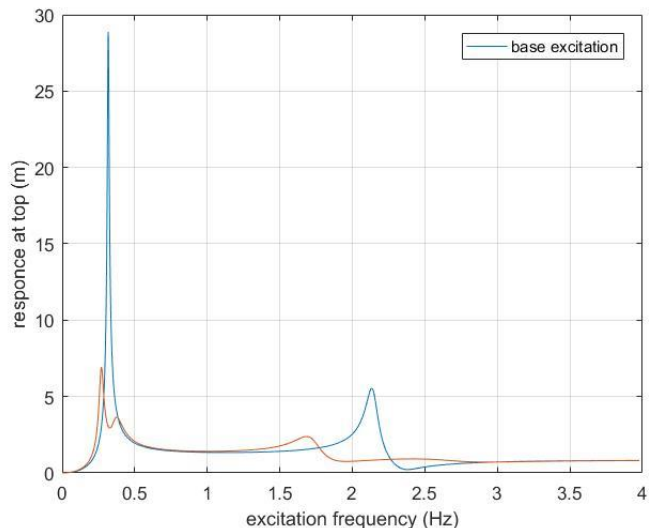

(a)

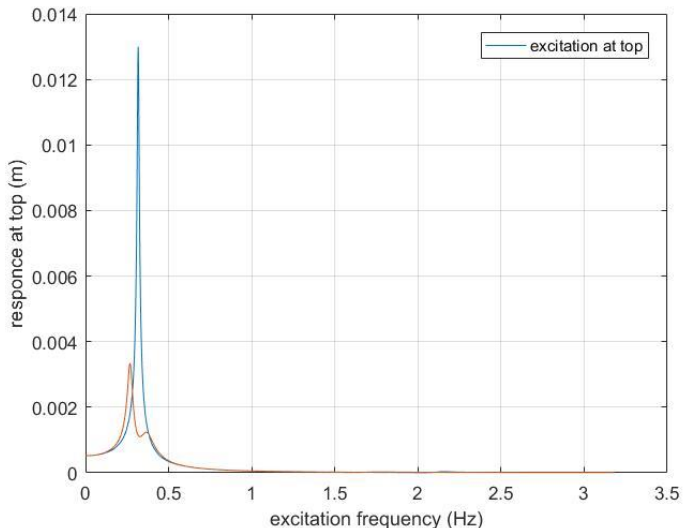

(b)

Figure 21: Transfer functions for the displacement at the top of the wind turbine tower, controlled with 2TMDs, due to (a) base excitation, and (b) excitation at top. 
In Table 3 are the optimum results after the implementation of 2TMDs that control the first 2 natural frequencies of the wind turbine tower before control, with a mass ratio of $10 \%$ and a damping ratio of $15 \%$.

\begin{tabular}{lllll}
\hline Excitation & $\max \left|u_{\text {top }}\right|(m)$ & $\max \left|a_{\text {top }}\right|\left(\mathrm{m} / \mathrm{sec}^{2}\right)$ & $\max \left|u_{\text {relativeTMD }}\right|(m)$ & $\max \left|u_{\text {relativeTMD }}\right|(m)$ \\
\hline JMA (1995) & 0.3264 & 9.3866 & 0.4389 & 0.1124 \\
TABAS & 0.7471 & 10.4754 & 1.2580 & 0.0894 \\
$\bar{F}_{N}(t)$ & 1.3515 & 3.2665 & 1.0183 & 0.0131 \\
\hline
\end{tabular}

Table 3: Results after the implementation of 2 TMDs of a mass ratio of $10 \%$ and a damping ratio of $15 \%$.

In order to calculate the exact value of the new damping ratio, the isolated system, with the 2 TMDs, is subjected to a free vibration with initial conditions, which in this case are according to the first modal eigenform of the wind turbine tower before control, with the initial conditions of the degrees of freedom of the TMDs to be equal to the respective degrees of freedom of the wind turbine tower which are related. More specifically, the value of the new damping ratio is calculated as in Eq.(48), where $T$ is the time between two consecutive peaks of the dynamic response of the system, as shown in Figure 22 . The new damping ratio of the system equals to $10.86 \%$.

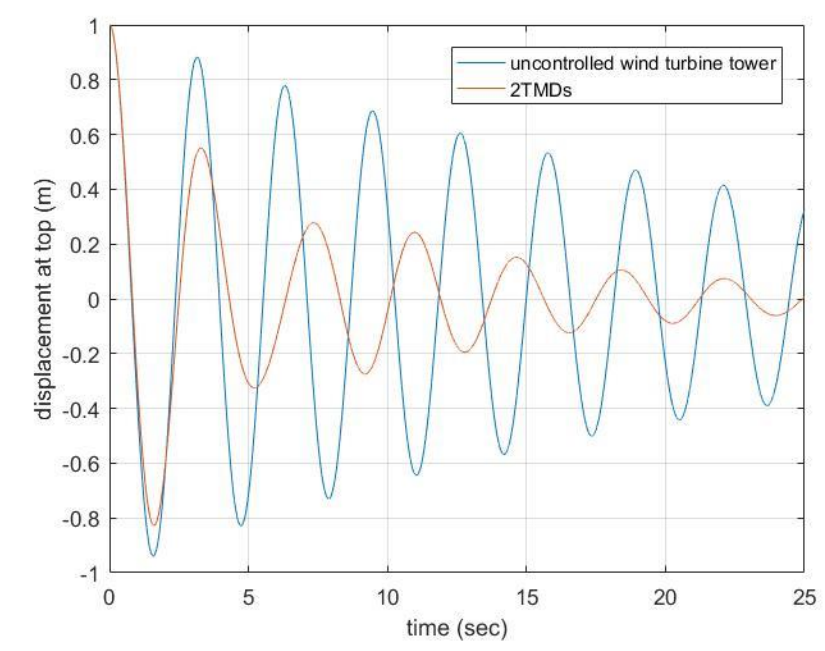

Figure 22: Dynamic response of the isolated system, with the 2TMDs, to a free vibration with initial conditions. 


\section{Test case 4: Single KDamper placed on top of the wind turbine tower}

The mass ratio, the damping ratio and the stiffness $k_{P}$ have the value $10 \%, 15 \%$ and 454.6 $\mathrm{kN} / \mathrm{m}$ (as in test case 2 with $10 \%$ mass ratio) respectively.

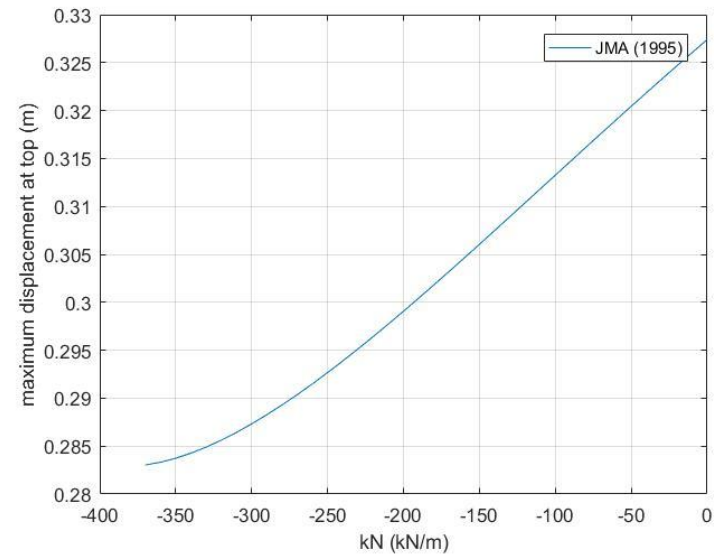

(a)

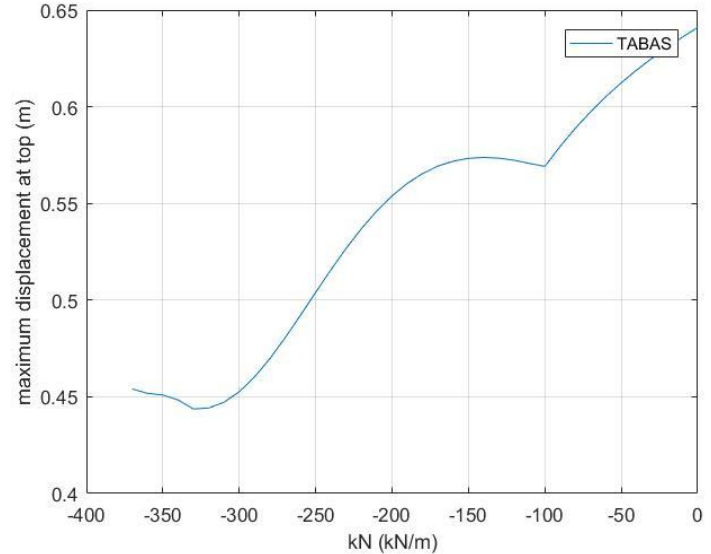

(b)

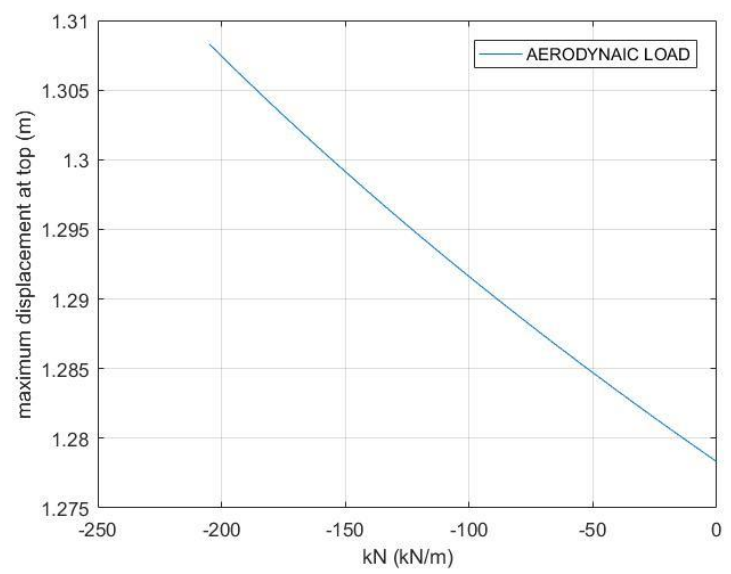

(c)

Figure 23: Variation of the maximum displacement at the top of the wind turbine tower on the negative stiffness element $k_{N}$.

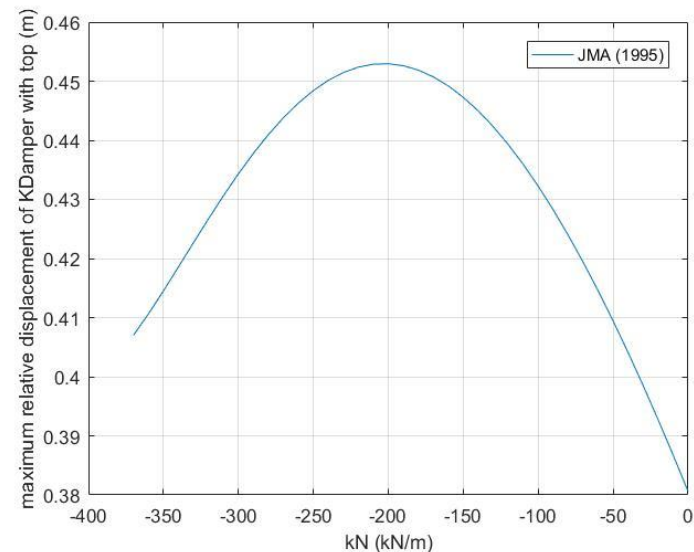

(a)

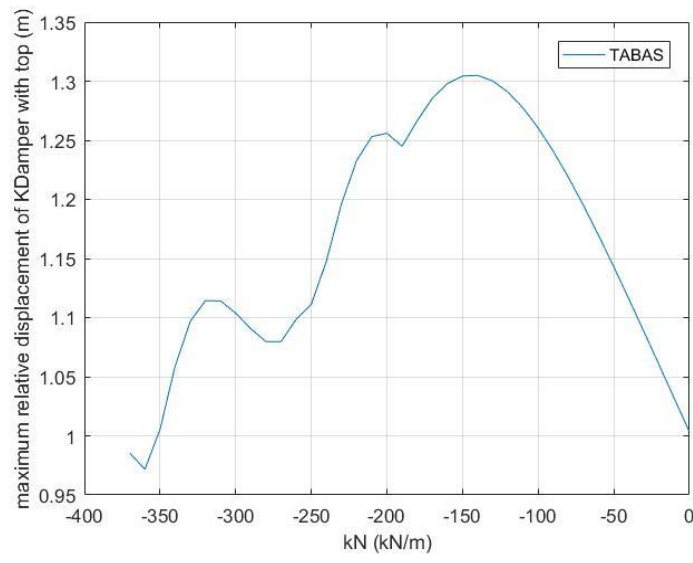

(b) 


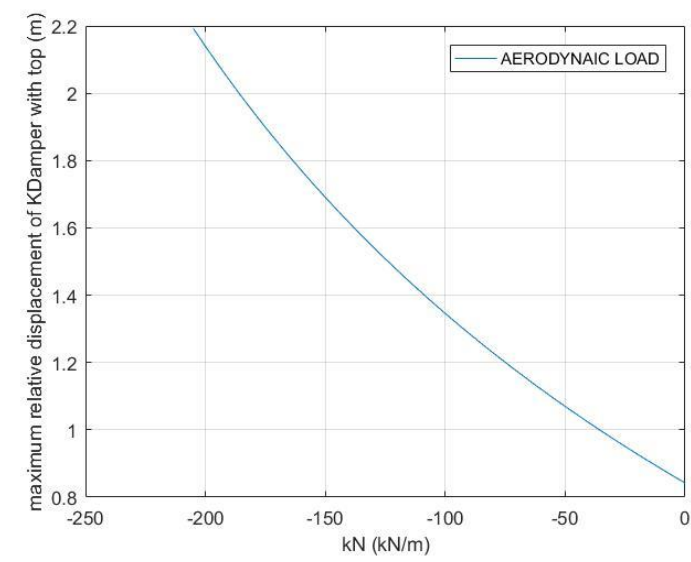

(c)

Figure 24: Variation of the maximum relative displacement of the KDamper and the top of the wind turbine tower on the negative stiffness element $k_{N}$.

In Figure 25 the Transfer functions are shown, for the wind turbine tower controlled with a KDamper with a mass ratio of $10 \%$, a damping ratio of $15 \%, k_{P}=454.6 \mathrm{kN} / \mathrm{m}$ and a negative stiffness element of $-200 \mathrm{kN} / \mathrm{m}$.

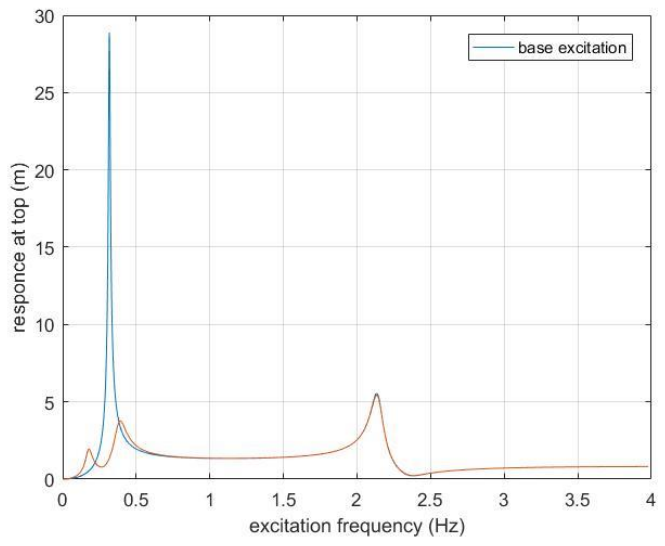

(a)

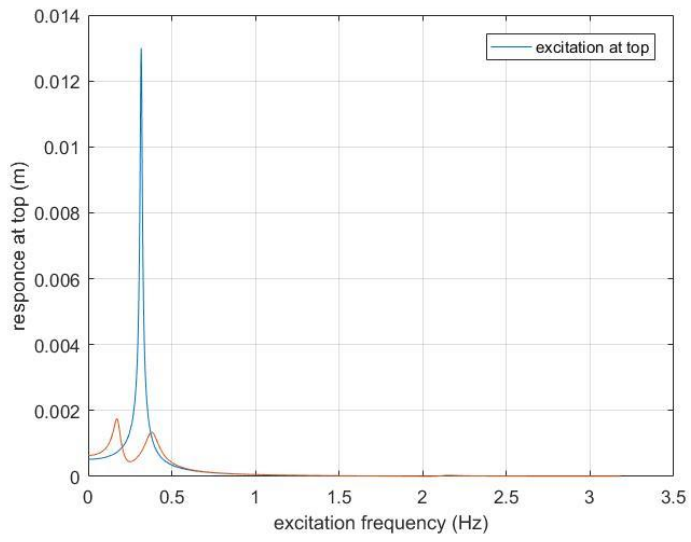

(b)

Figure 25: Transfer functions for the displacement at the top of the wind turbine tower, controlled a KDamper, due to (a) base excitation, and (b) excitation at top.

In Table the optimum results after the implementation of a KDamper, are presented, with a mass ratio of $10 \%$, a damping ratio of $15 \%, k_{P}=454.6 \mathrm{kN} / \mathrm{m}$ and a negative stiffness element of $-200 \mathrm{kN} / \mathrm{m}$.

\begin{tabular}{llll}
\hline Excitation & $\max \left|u_{\text {top }}\right|(m)$ & $\max \left|a_{\text {top }}\right|\left(m / \mathrm{sec}^{2}\right)$ & $\max \left|u_{\text {relativeKDamper }}\right|(m)$ \\
\hline JMA (1995) & 0.2991 & 11.9553 & 0.4530 \\
TABAS & 0.5539 & 11.7323 & 1.2560 \\
$\bar{F}_{N}(t)$ & 1.3074 & 3.2665 & 2.1393 \\
\hline
\end{tabular}

Table 4: Results after the implementation of a KDamper of a mass ratio of $10 \%$, a damping ratio of $15 \%$, $k_{P}=454.6 \mathrm{kN} / \mathrm{m}$ and a negative stiffness element of $-200 \mathrm{kN} / \mathrm{m}$. 
The implementation of the KDamper leads to a new system with reduced displacements along the tower of the wind turbine and higher damping ratio. In order to calculate the value of the new damping ratio, the isolated system is subjected to a free vibration with initial conditions, which in this case are according to the first modal eigenform of the wind turbine tower before control, with the initial condition of the KDamper equal to the initial condition at the top of the wind turbine tower. However, the new damping ratio of the system cannot be calculated as in the previous Test cases, due to the fact that the maximum values of the response (Figure 26), for a free vibration with initial conditions, does not follow an exponential distribution.

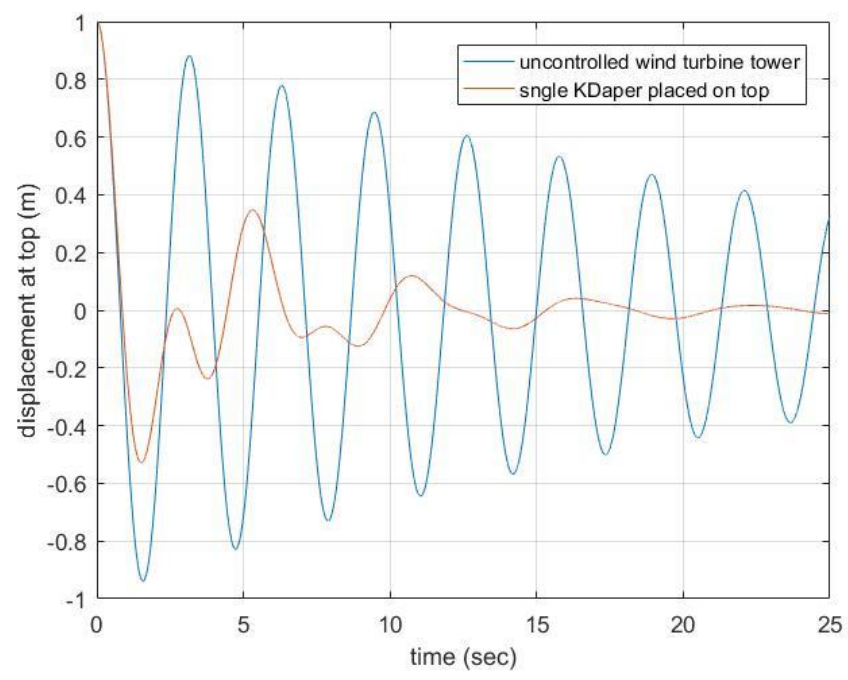

Figure 26: Dynamic response of the isolated system, with the KDamper, to a free vibration with initial conditions.

Finally, the static stability margin $\varepsilon$ is calculated as in 3.2 (Test case 4). With the installed parameters that are presented in 4.1 (Test case 4), the value for the static stability margin is 1.0283 or $102.83 \%$.

\subsection{Comparison of the top displacement}

In Table 5, the maximum displacement of the top of the wind turbine tower is presented, for each excitation and test case respectively, as well as the reduction percentage in relation to the top displacement of the uncontrolled wind turbine.

\begin{tabular}{llll}
\hline Test case & JMA (1995) & TABAS & $\bar{F}_{N}(t)$ \\
\hline Uncontrolled & $0.3682 \mathrm{~m}$ & $0.9607 \mathrm{~m}$ & $1.436 \mathrm{~m}$ \\
Single TMD & $0.3273 \mathrm{~m}$ & $0.6408 \mathrm{~m}$ & $1.2783 \mathrm{~m}$ \\
Reduction & $11.10 \%$ & $33.29 \%$ & $10.98 \%$ \\
2 TMDs & $0.3264 \mathrm{~m}$ & $0.7471 \mathrm{~m}$ & $1.3515 \mathrm{~m}$ \\
Reduction & $11.35 \%$ & $22.23 \%$ & $5.88 \%$ \\
Single KDamper & $0.2991 \mathrm{~m}$ & $0.5539 \mathrm{~m}$ & $1.3074 \mathrm{~m}$ \\
Reduction & $18.77 \%$ & 42.34 & $8.95 \%$ \\
\hline
\end{tabular}

Table 5: maximum top displacement for each test case respectively. 


\section{CONCLUSIONS}

The KDamper concept can provide a realistic alternative to the existing vibration isolation systems used for the design of wind turbines. The implementation of the KDamper leads to a drastic reduction of the wind turbines dynamic response, in most cases even greater than that of the TMD, offering high damping properties at the same time. The reliability and simplicity of the system are also advantages that render the devise suitable for various technological implementations. Moreover, the inherent non-linear nature of the negative stiffness force can be exploited to offer further potential advantages of the KDamper concept, such as robustness, broadband response and energy sinks.

\section{Acknowledgements}

This research has been co-financed by the Operational Programme «Human Resources Development Program, Education and Lifelong Learning» of the Action «Strengthening Human Resources Research Potential via Doctorate Research», of ESPA 2014-2020 with the cofinancing of the European Social Fund - ESF and Greek National Funds.

\section{REFERENCES}

[1] I. Antoniadis, D. Chronopoulos, V. Spitas, D. Koulocheris, Hyper-damping properties of a stable linear oscillator with a negative stiffness element. Journal of Sound and Vibration, 346, 37-52, 2015.

[2] A. Carella, M. Brennan, T. Waters, Static analysis of a passive vibration isolator with quasi-zero-stiffness characteristic. Journal Sound and Vibration 301, 678-689, 2007.

[3] CEN/TC250, Eurocode 1: Actions on structures-General actions-Part 1-4: Wind actions. prEN 1991-1-4, 2004.

[4] N. Debnath, S. K. Deb, A. Dutta, Multi-modal vibration control of truss bridges with tuned mass dampers under general loading. Journal of Vibration and Control, DOI: $10.1177 / 1077546315571172,2015$.

[5] J.P. Den Hartog, Mechanical Vibrations, 4th Edition. McGraw Hill, 1956.

[6] S. Elias, V. Matsagar, T. K. Datta, Effectiveness of distributed tuned mass dampers for multi-mode control of chimney under earthquakes. Engineering Structures 124, 2016.

[7] B. Fitzgerald, B. Basu. Structural control of wind turbines with soil interaction. Engineering Structures, 111, 131-151, 2016.

[8] H. Frahm, Device for Damping Vibrations of Bodies. US patent \#989958, 1909.

[9] M. O. L. Hansen, Aerodynamics of Wind Turbines. Earth-scan, London, 2008.

[10] R. Ibrahim, Recent advances in nonlinear passive vibration isolators. Journal of Sound and Vibration 314, 371-452, 2008.

[11] G. Jackson, Njiri, S. Dirk, State-of-the-art in wind turbine control: Trends and challenges. Renewable and Sustainable Energy Reviews 60, 377-393, 2016. 
[12] J. M. Jonkman, Dynamics modeling and loads analysis of an offshore floating wind turbine. Technical Report NREL/TP-500-41958, 2007.

[13] M. Lackner, M. Rotea. Passive structural control of offshore wind turbines. Wind Energy 14(3):373-88, 2011.

[14] J. Mayet, H. Ulbrich, First-order optimal linear and nonlinear detuning of centrifugal pendulum vibration absorbers, Journal of Sound and Vibration 335, 34-54, 2015.

[15] W. Molyneaux, Supports for vibration isolation. ARC/CP-322, Aeronautical Research Council, Great Britain, 1957.

[16] J. Ormondroyd, J. P. Den Hartog, The Theory of Dynamic Vibration Absorber. Trans. ASME, APM-50-7, 9-22, 1928.

[17] D. L. Platus, Negative-stiffness-mechanism vibration isolation systems. SPIE's International Symposium on Optical Science, Engineering, and Instrumentation, 98-105, 1999.

[18] A. Quiligan, A. O'Connor, V. Pakrashi, Fragility analysis of steel and concrete wind turbine towers. Engineering Structures, 36, 270-282, 2012.

[19] M. Rahman, Z. C. Ong, W. T. Chong, S. Julai, S. Y. Khoo, Performance enhancement of wind turbine systems with vibration control: A review. Renewable and Sustainable Energy Reviews 51, 43-54, 2015.

[20] E.J. Sapountzakis, P.G. Syrimi, I.A. Pantazis, I.A. Antoniadis, KDamper concept in seismic isolation of bridges. 1st International Conference on Natural Hazards \& Infrastructure (ICONHIC 2016), Chania, Crete, Greece, June 28-30, 2016.

[21] I. Vassilopoulou, C. Gantes, I. Gkimousis, Response of Cable Networks under Wind Loading. 7th National Conference on Steel Structures, Volos, September 29-30 - October 1, 2011.

[22] A. Younespour, H. Ghaffarzadeh, Structural active vibration control using active mass damper by block pulse functions. Journal of Vibration and Control, 21(14), 2787-2795, 2015. 